\title{
Functional diversity of 2-oxoglutarate/Fe(II)-dependent dioxygenases in plant metabolism
}

\author{
Scott C. Farrow and Peter J. Facchini* \\ Department of Biological Sciences, University of Calgary, Calgary, AB, Canada
}

\section{Edited by:}

Stefan Martens, Edmund Mach

Foundation, Italy

Reviewed by:

Reuben Peters, lowa State

University, USA

Andre O. Hudson, Rochester

Institute of Technology, USA

Heribert Warzecha, Technische

Universitaet Darmstadt, Germany

*Correspondence:

Peter J. Facchini, Department of Biological Sciences, University of Calgary, 2500 University Drive NW,

Calgary, AB T2N 1N4, Canada

e-mail:pfacchin@ucalgary.ca
Oxidative enzymes catalyze many different reactions in plant metabolism. Among this suite of enzymes are the 2-oxoglutarate/Fe(II)-dependent dioxygenases (2-ODDs). Cytochromes P450 (CYPs) as often considered the most versatile oxidative enzymes in nature, but the diversity and complexity of reactions catalyzed by 2-ODDs is superior to the CYPs. The list of oxidative reactions catalyzed by 2-ODDs includes hydroxylations, demethylations, desaturations, ring closure, ring cleavage, epimerization, rearrangement, halogenation, and demethylenation. Furthermore, recent work, including the discovery of 2-ODDs involved in epigenetic regulation, and others catalyzing several characteristic steps in specialized metabolic pathways, support the argument that 2-ODDs are among the most versatile and important oxidizing biological catalysts. In this review, we survey and summarize the pertinent literature with a focus on several key reactions catalyzed by 2-ODDs, and discuss the significance and impact of these enzymes in plant metabolism.

Keywords: 2-oxoglutarate/Fe(II)-dependent dioxygenase, primary metabolism, specialized metabolism, DNA and histone demethylation, iron sensing

\section{INTRODUCTION}

The first reported dioxygenase activity was pyrocatechase from Pseudomanas spp., which catalyzes the 1,2-intradiol cleavage of pyrocatechin to muconic acid (Hayaishi and Hashimoto, 1950). In this reaction, both atoms of molecular oxygen are incorporated into the muconic acid product, leading to use of the term "di"oxygenase (Hayaishi et al., 1956). By definition, dioxygenases have the ability to incorporate two atoms of molecular oxygen into one or more substrates. However, this definition can be ambiguous owing to the number of different dioxygenase types, which vary by the nature of their co-factor and co-substrate dependence. This review is focused on the mononuclear iron dioxygenases, with particular emphasis on a specific sub-class, the 2-oxoglutarate/Fe(II)-dependent dioxygenases (2-ODDs).

2-ODDs are non-heme proteins belonging to a large superfamily that are ubiquitously distributed throughout nature, and occur in bacteria, fungi, plants, and vertebrates (De Carolis and De Luca, 1994; Martens et al., 2010). The landmark discovery of the first 2-ODD revealed its hydroxylation capacity for prolyl and lysyl amino acid residues, and established the necessary factors required for enzyme function (Hutton et al., 1967). 2-ODDs are dependent on ferrous iron as a co-factor for the binding of molecular oxygen and subsequent oxidative reactions. In essentially all cases, 2-ODDs couple the two-electron oxidation of the prime substrate $[\mathrm{S}]$ to the oxidative decarboxylation of the distinctive co-substrate-2-oxoglutarate (2OG) - giving rise to succinate and carbon dioxide (Scheme 1; Wilmouth et al., 2002; Zhang et al., 2004; Flashman and Schofield, 2007; Hangasky et al., 2013). The oxidation of the prime (S) substrate leads to the formation of specific products (SO).
In addition to $2 \mathrm{OG}$ and ferrous iron, 2-ODDs activity is usually increased by the addition of catalase and ascorbate. Catalase serves as a protecting agent from hydrogen peroxide (Prescott and John, 1996), whereas ascorbate-although not always essential—supports enzyme function by completing spontaneous-uncoupled reactions (Clifton et al., 2006) and is thought to assist with enzymatic cycles by maintaining the ferrous iron state (De Carolis and De Luca, 1994; Prescott and John, 1996).

2-ODDs facilitate numerous oxidative reactions including hydroxylations, halogenations, desaturations, epimerization, cyclizations, and ring formation, ring fragmentation, $\mathrm{C}-\mathrm{C}$ bond cleavage, re-arrangements, demethylations, and demethylenations (Clifton et al., 2006; Flashman and Schofield, 2007; Loenarz and Schofield, 2008; Tarhonskaya et al., 2014). This impressive list of reactions reveals the versatility of these enzymes in catalyzing many reactions that are still not possible using synthetic chemistry (Flashman and Schofield, 2007). The significance of 2ODDs is underscored by their widespread roles in biosynthetic pathways essential for normal organismal function, or that lead to high-valued specialized metabolites.

The Arabidopsis thaliana genome contains more than 130 2 -ODD genes, representing approximately $0.5 \%$ of the total gene complement (Kawai et al., 2014). However, only a handful of plant 2-ODDs have been functionally characterized. Extrapolating from the number of 2-ODD genes in Arabidopsis, a plethora of reactions and roles for 2-ODDs in other plant species can be predicted. Given the known importance of 2-ODDs in plant metabolism, the continued functional characterization of 2-ODDs is essential. Here we describe known biochemical functions for plant 2-ODDs, with a focus 


$$
2 \mathrm{OG}+\mathrm{O}_{2}+\mathrm{S} \rightarrow \text { succinate }+\mathrm{CO}_{2}+\mathrm{SO}
$$

Scheme 1 | Catalytic mechanism for 2-oxoglutarate-dependent dioxygenases. Abbreviations: $\mathrm{S}$, prime substrate; $\mathrm{SO}$, oxidized prime substrate.

on recent discoveries and the impact of 2-ODDs on plant metabolism.

\section{STRUCTURAL AND MECHANISTIC FEATURES OF 2-OXOGLUTARATE/Fe(II)-DEPENDENT DIOXYGENASES}

Structural analyses of leucoanthocyanidin synthase (LDOX; Wilmouth et al., 2002; PDB:1GP4), 1-aminocyclopropane-1carboxylic acid oxidase (ACCO; Zhang et al., 2004; PDB:1W9Y) and several related 2-ODDs have revealed canonical structural features, including a double stranded $\beta$-helix core fold known as jellyroll topology that supports and protects a catalytic triad of $\mathrm{Fe}$ (II) binding residues (Clifton et al., 2006). These residues are comprised of a highly conserved, but not ubiquitous, $\mathrm{HX}(\mathrm{D} / \mathrm{E}) \mathrm{X}_{n} \mathrm{H}$ triad motif that is essential for binding $\mathrm{Fe}(\mathrm{II})$ (Figure 1). Residues conferring 2OG binding are less conserved and are usually characteristic of 2-ODD sub-families, whereas those linked to binding of the prime substrate are variable, but might involve features in proximity to the active core (Loenarz and Schofield, 2008).

Detailed crystallographic, spectroscopic and kinetic analyses have revealed mechanistic features that are apparently ubiquitous for the formation of the high-valent iron-oxo intermediate responsible for oxidation of the prime substrate. The consensus mechanism involves binding of ferrous iron, which displaces two water molecules and permits the bidentate binding of $2 \mathrm{OG}$ (C-1 carboxyl, C-2 keto). Binding of the prime substrate weakens an additional water molecule and exposes another iron binding site for molecular oxygen. Subsequent decarboxylation of $2 \mathrm{OG}$ gives rise to $\mathrm{CO}_{2}$ and a succinate bound iron-oxo intermediate. The iron-oxo intermediate is essential for oxidation of the prime substrate (Figure 2A), and has been likened to Fenton chemistry (Prescott and John, 1996; Groves, 2006). Oxidative mechanisms are specific to each prime substrate, and several different mechanisms have been proposed (Wilmouth et al., 2002). Some atypical 2-ODDs, such as an enzyme involved in ethylene formation, have a $2 \mathrm{OG}$ binding motif, but utilize ascorbate instead of $2 \mathrm{OG}$ for formation of the reactive iron-oxo intermediate (See below for details of this mechanism; Hausinger, 2004).

\section{2-ODDs IN PRIMARY METABOLIC NETWORKS DNA REPAIR}

Alkylating agents are ubiquitous throughout nature and are a significant contributor to RNA and DNA damage, as well as tumorigenesis (Mielecki et al., 2012). In depth analysis of their target substrates has revealed a capacity for nucleic acid alkylation, which leads to toxic, mutagenic or neutral chemical derivatives (Drabløs et al., 2004). As a means to counter these potentially deleterious chemicals, several organisms have evolved repair mechanisms. One mechanism has been described for Escherichia coli ALKB proteins, which are 2-ODDs capable of repairing a number of modifications to the $\mathrm{N}^{1}$ and $\mathrm{N}^{3}$ positions of adenine and cytosine, respectively (Lindahl et al., 1988; Mielecki et al., 2012). Until recently, no active ALKB homologs were known from plants. However, a homolog of human alkbh2 and alkbh3 has been identified in Arabidopsis thaliana (Meza et al., 2012). Recombinant AtALKBH2 prefers $d s$ DNA over $s s$ DNA, and is capable of reversing etheno lesions, which is also a function of human ALKBH2 (Figure 2B). Furthermore, Arabidopsis thaliana mutants with a defective alkbh2 were sensitive to the methylating agent methylmethanesulphonate, which supports a role for ALKBH2 in the removal of deleterious methyl lesions from plant genomes. Sequence and functional similarities between human and plant $\mathrm{ALKBH} 2$ suggests that these proteins are true orthologs (Meza et al., 2012).

Sequence similarity among AtALKB homologs is insufficient for the assignment of protein function. Although AT3G14160 (NP_566479.5), and AT1G11780 (NP_172643.1) display the highest degree of sequence similarity to the characterized and functional E. coli ALKB, these Arabidopsis proteins did not show DNA repair activity in phage reactivation assays (Meza et al., 2012). The same observation is true for human ALKBH1, which shows high homology with functional E. coli ALKB, yet only ALKBH2 and ALKBH3 possess DNA repair activities (Mielecki et al., 2012). Other ALKB homologs from human and Arabidopsis appear to have different functions (Meza et al., 2012).

\section{HISTONE DEMETHYLATION}

Histone methylation plays a fundamental role in gene activation or repression in eukaryotic species (Cho et al., 2012). Although the covalent modification of histone residues is usually reversible, the reversibility of methylations was questionable (Tsukada et al., 2006) until the landmark discovery of the first histone demethylase (Shi et al., 2004). The reversible methylation and demethylation of histone residues are key components in the epigenetic modulation of gene expression. Several histone demethylases have been identified and characterized from numerous eukaryotes, and these are categorized into two main categories: (i) flavin adenine dinucleotide oxidase demethylases and (ii) 2-ODD demethylases.

Characterization of plant homologs representing both families has revealed numerous physiological roles including the regulation of flowering time (Jeong et al., 2009; Lu et al., 2010; Yang et al., 2010), de-etiolation (Charron et al., 2009), female gametophyte development (Pagnussat et al., 2005), brassinosteroid signaling (Yu et al., 2008), floral organ development (Sun and Zhou, 2008) and circadian regulation (For a review see: Jones et al., 2010; Chen et al., 2011; Lu et al., 2011). Critical among these enzymes are the "Jumonji" (Takeuchi et al., 1995) class of 2-ODD demethylases (JmjC).

Recently, two JmjC genes, Jmj20 and Jmj22, encoding 2-ODDs were linked to seed development in Arabidopsis. Interestingly, $J m j 20$ and Jmj22 are induced by light via the activation of cytochrome B. Jmj20 and Jmj22 act redundantly to reverse repressive histone methylation, which allows transcription of key gibberellin biosynthetic genes, gibberellin 3-oxidase and gibberellin 2-oxidase. The subsequent increase in the levels of active gibberellins stimulates seed germination (Cho et al., 2012). 


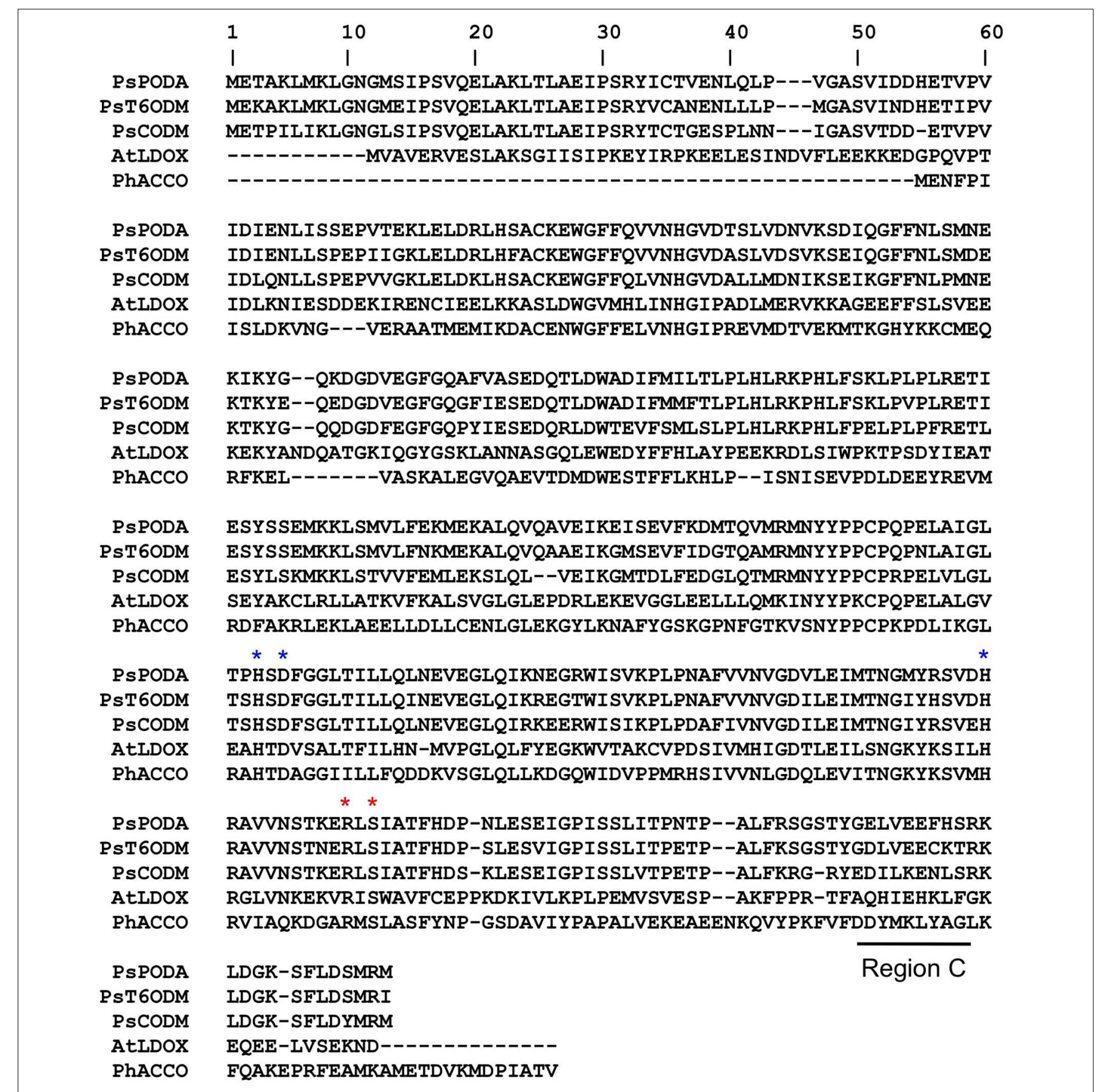

FIGURE 1 | Sequence alignments of $O$-demethylases from Papaver somniferum and 2-ODDs from other plants for crystal structures have been determined. PSCODM, codeine O-demethylase; PsT6ODM, thebaine 6-O-demethylase; PsPODA, protopine O-dealkylase; AtLDOX,

leucoanthocyanidin dioxygenase; PhACCO, 1-aminocyclopropane-1-carboxylic acid oxidase. Blue asterisks indicate a conserved catalytic triad motif $\left(\mathrm{H}_{x} \mathrm{D}_{\mathrm{x}} \mathrm{H}\right)$. Red asterisks indicate proposed $20 \mathrm{G}$ binding residues. Region $\mathrm{C}$ contains residues associated with the regiospecific 3-O-demethylation of thebaine (Runguphan et al., 2012). Comprehensive alignments and phylogenetic trees of numerous plant 2-ODDs have been reported (Kawai et al., 2014).
Another 2-ODD, Jmj703, was linked to plant cell division and stem elongation via the demethylation of mono-, di-, and tri-methylated lysine- 4 residues of histone subunit 3 (Chen et al., 2013). Interestingly, loss-of-function mutants displayed a dwarf phenotype and cytokinin oxidase genes (CKX), which control the deactivation of cytokinin, were expressed at elevated levels compared with wild type plants. Additionally, the methylation status of the promoter region of CKX genes was increased in mutant plants, suggesting that Jmj703 plays a role in regulating the expression of $C K X$ genes and the proper plant growth and development via the modulation of active cytokinin pools. 


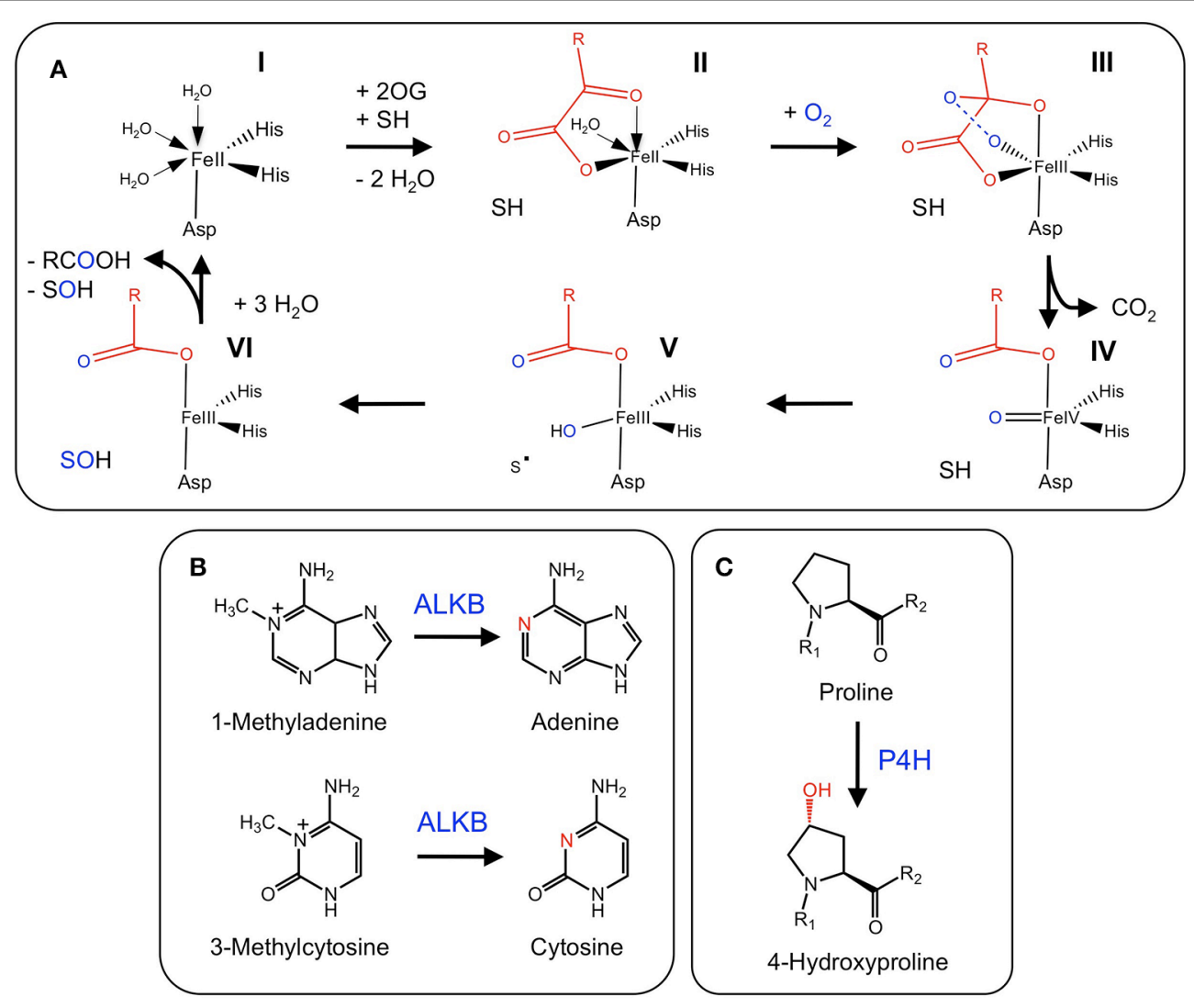

FIGURE 2 | (A) Proposed mechanisms of 2-oxoglutarate binding and formation of the reactive iron-oxo intermediate for the oxidation of the prime substrate. (I) Ferrous iron binds to the active site of the jellyroll structure. (II) Addition of 2-oxoglutarate displaces two water molecules and permits the bidentate binding of 2-oxoglutarate. Subsequent binding of the prime substrate $(\mathrm{SH})$ in (II) vacates a third binding site for molecular oxygen (III). Oxidative decarboxylation of 2-oxoglutarate (III-IV) yields the reactive iron-oxo intermediate and succinate. (IV-VI) Hydrogen abstraction and two-electron oxidation of the prime substrate leads to the formation of the product $(\mathrm{SOH})$ and the release of succinate for subsequent enzyme cycles (Adapted from Tarhonskaya et al., 2014). (B) DNA repair via the demethylation of $N_{6}$ and $N_{1}$ of adenine and cytosine, respectively, by ALKB. (C) $\mathrm{P} 4 \mathrm{H}$ hydroxylates proline residues leading to the formation of 4-hydroxyproline. $\mathrm{P} 4 \mathrm{H}$ is involved in the post-translational modification of structural proteins. A subclass of these proteins (HIF) is involved in oxygen sensing in mammals, whereas and iron-sensing role has been proposed for the equivalent homologs in plants.

\section{POST-TRANSLATIONAL MODIFICATION AND IRON SENSING}

Post-translational modifications (PTMs) are one of several methods whereby organisms extend or alter protein function. One of the most abundant PTMs is proline hydroxylation, which is catalyzed by the 2-ODD, proly 4-hydroxylase (P4H) (Gorres and Raines, 2010). The product of $\mathrm{P} 4 \mathrm{H}$, 4-hydroxyproline, occurs in numerous proteins in animals and is found in different plant glycoproteins (Soares et al., 2011). In animals, 4-hydroxyproline confers structural integrity to collagen. Proline PTMs also occur in several structural proteins and are essential for normal plant growth and development. Although many P4Hs have been characterized from animals (Myllyharju, 2003), the biochemical functions of only two Arabidopsis $\mathrm{P} 4 \mathrm{Hs}$ have been determined (Hieta and Myllyharju, 2002; Tiainen et al., 2005). Arabidopsis P4Hs exhibit proline 4-hydroxylation activity, but show a variable substrate range and kinetic properties suggesting that each protein possesses a unique function (Figure 2C). Although authentic targets have not been identified, Arabidopsis $\mathrm{P} 4 \mathrm{H}$ genes are highly expressed in roots and display differential responses to various stresses (Vigani et al., 2013).
The hypoxia-inducible transcription factor (HIF) is regulated by a $\mathrm{P} 4 \mathrm{H}$ subclass (HIF-P4H). Under normoxic conditions, the $\mathrm{HIF} \alpha$ sub-unit is constitutively synthesized and contains a critical 4-hydroxy proline residue. The presence of 4-hydroxyproline is essential for rapid and continuous proteasomal degradation. Alternatively, under hypoxic conditions, HIF-P4H is inactive and the proline residue is no longer modified. Consequently, HIF $\alpha$ is salvaged and can form a stable dimer with the HIF $\beta$ subunit. The dimer is translocated into the nucleus where it docks with HIF-responsive elements, which activates a cascade of hypoxiaresponsive genes. As such, HIF-P4Hs are thought to be key oxygen sensors in animals (Vigani et al., 2013).

In plants, the functions of HIF-P4H homologs are not well understood. One hypothesis is that HIF-P4Hs in plants modulate metabolic changes during iron starvation. Interestingly, several of these changes involve the induction of 2-ODDs with roles in the reutilization of iron (Jin et al., 2007; Lan et al., 2011) or the scavenging of iron from the soil (Kobayashi et al., 2001). Moreover, HIF-P4Hs have a relatively low $K_{m}$ for iron (Hieta and Myllyharju, 2002; Tiainen et al., 2005). Whereas animal 
HIF-P4Hs sense oxygen, plant homologs are thought to function as iron sensors by monitoring the availability of iron. Taken together, a link might exist between specific 2-ODDs, such as $\mathrm{P} 4 \mathrm{H}$, and iron deficiency responses via some specific metabolic reprogramming. Such advancements in the field of plant nutrient sensing and signaling could contribute to solutions addressing several global agricultural challenges (Vigani et al., 2013).

\section{GIBBERELLIN BIOSYNTHESIS AND CATABOLISM}

Gibberellins (GAs) are a group of diterpene-derived plant growth regulators that play a key role in many growth and developmental processes including stem elongation, leaf expansion, flower development, and germination (MacMillan, 2001). The well-defined biosynthesis of GAs includes several 2-ODDs that are responsible for several structural modifications (Yamaguchi, 2008) (Figure 3). The 2-ODD GA 20-oxidase (GA20ox) catalyzes the three-step oxidation of inactive $\mathrm{GA}_{12}$ or $\mathrm{GA}_{53}$ to the immediate precursors of active GAs (Lange et al., 1994a; Xu et al.,
1995; Lange, 1997). Activation of the GA scaffold is performed by other 2-ODDs, GA 3-oxidases (GA3ox), which shows strict regio-specificity for the $\mathrm{C}-3$ position of $\mathrm{GA}_{5}, \mathrm{GA}_{9}$, and $\mathrm{GA}_{20}$ (Chiang et al., 1995; Lange et al., 1997). In contrast, GA 2-oxidases (GA2ox) play a role in GAs catabolism via C-2 hydroxylation of the GA backbone (Thomas et al., 1999; Schomburg et al., 2003; Lee and Zeevaart, 2005). Interestingly, pumpkin (Cucurbita maxima L.) contains one additional enzyme, GA7 oxidase (GA7ox), which catalyzes the C-7 oxidation of $\mathrm{GA}_{12}$ aldehyde to produce the carboxylic acid moiety of $\mathrm{GA}_{15}$. The occurrence of this enzyme in pumpkin is unusual because the same reaction is also catalyzed by a highly conserved CYP (CYP88A) (Hedden et al., 2002). The occurrence of functionally redundant enzymes in pumpkin might reflect the occurrence of disparate and isolated GA pathways leading to different compounds (Lange et al., 1994b).

GA metabolism in plants and fungi is notably different at later metabolic stages. In fungi, CYPs are the prominent enzyme

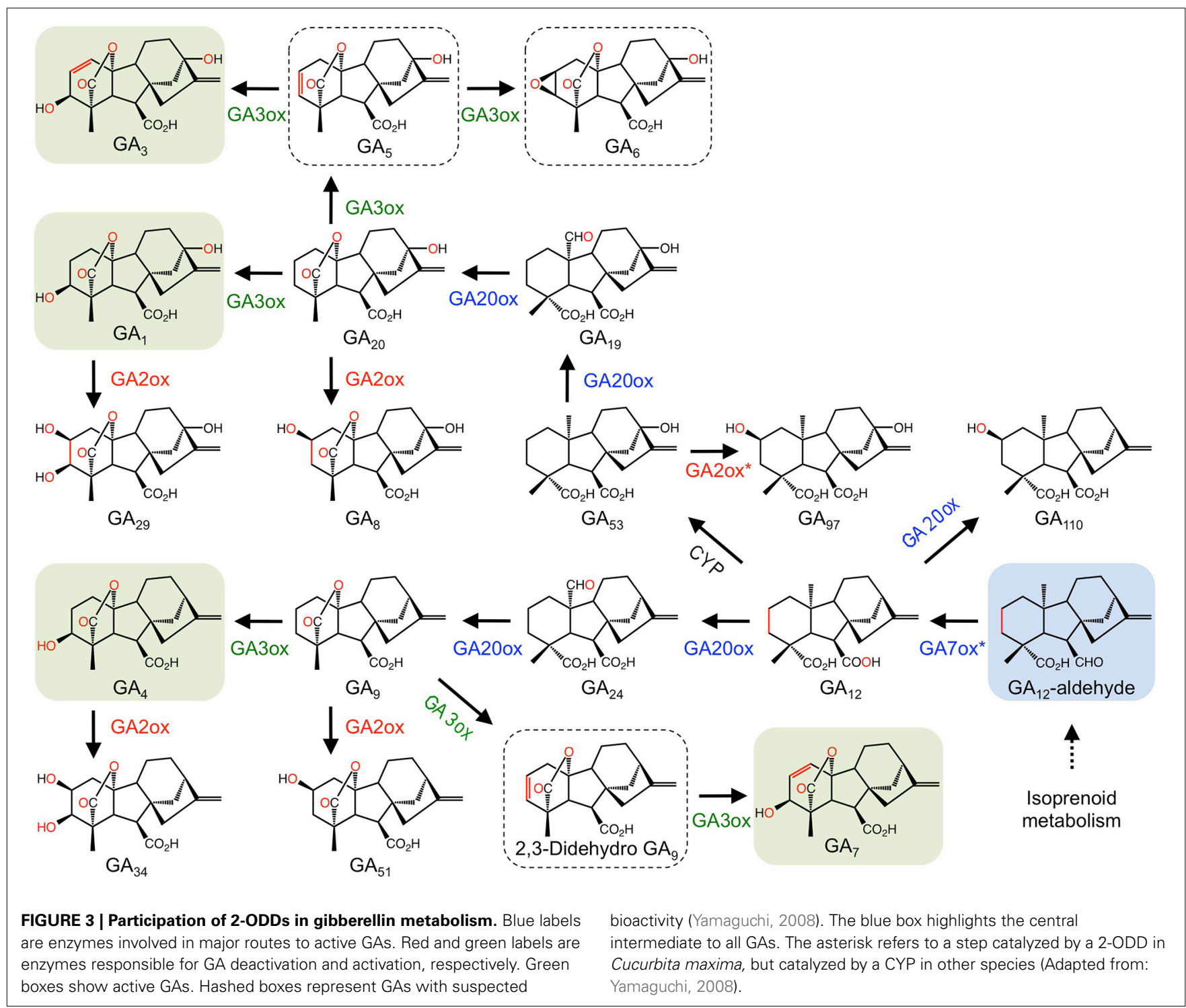


type catalyzing the biosynthesis of active GAs, whereas plants predominantly use 2-ODDs (Hedden et al., 2002). Occasionally, plants and fungi utilize both enzyme types (Lange et al., 1994b).

\section{ETHYLENE BIOSYNTHESIS}

The gaseous plant growth regulator ethylene has roles in several plant growth and developmental processes including senescence and fruit ripening. Ethylene biosynthesis begins with the conversion of $\mathrm{L}$-methionine to $S$-adenosyl-L-methionine (SAM) by SAM synthetase. SAM is converted to the immediate precursor to ethylene, 1- aminocyclopropane-1-carboxylic acid (ACC), by ACC synthase. The final step is catalyzed by the 2-ODD, ACC oxidase (ACCO; Figure 4A). Since the initial isolation of ACCO cDNAs (Nakajima and Mori, 1990; Van der Straeten et al., 1990), native and recombinant proteins have been characterized from several plants (Kende, 1993). An interesting feature of the ACCO reaction is the role of carbon dioxide in preventing auto-inactivation of the enzyme. Furthermore, despite having the conserved binding motif, ACCO does not utilize $2 \mathrm{OG}$ as a substrate. Instead, ascorbic acid acts as a twoelectron reductant critical to the catalytic mechanism (Hausinger, 2004). The generally accepted mechanistic model for ACCO involves the formation of bicarbonate, which is thought to occur via reaction of $\mathrm{CO}_{2}$ with an iron bound molecule. Binding of 1-aminocyclopropane-1-carboxylic acid followed by oxygen activation via ascorbate-mediated bicarbonate reduction leads to the formation of the iron-oxo intermediate, which subsequently oxidizes 1-aminocyclopropane-1-carboxylic acid leading to the production of ethylene, hydrogen cyanide, and carbon dioxide (Figure 4A).

\section{AUXIN CATABOLISM}

Indole-3-acetic acid or auxin (IAA) is a plant growth regulator with many key roles in plant growth and development. As such, IAA biosynthesis, transport, and signaling are highly regulated processes. The general model for IAA regulation involves a network of synthesis, degradation, conjugation, and transport (Woodward and Bartel, 2005). Despite knowledge of numerous IAA biosynthetic and conjugative enzymes, and an understanding of several transport mechanisms, the catabolism and degradation of IAA are not as well understood. Recently, a 2-ODD (DAO) from rice was shown to catalyze the irreversible inactivation of IAA to its oxindole derivative (OxIAA) (Figure 4B). The dao gene was linked with IAA catabolism by characterizing the dao mutant, which showed significantly higher levels of active IAA, and an apparent lack of OxIAA. Mutant dao plants also displayed several developmental abnormalities to male reproductive organs and were infertile. Moreover, unfertilized ovaries produced parthenocarpic seeds. As such, it was suggested that dao assists in the regulation of active IAA pools in rice flowers with

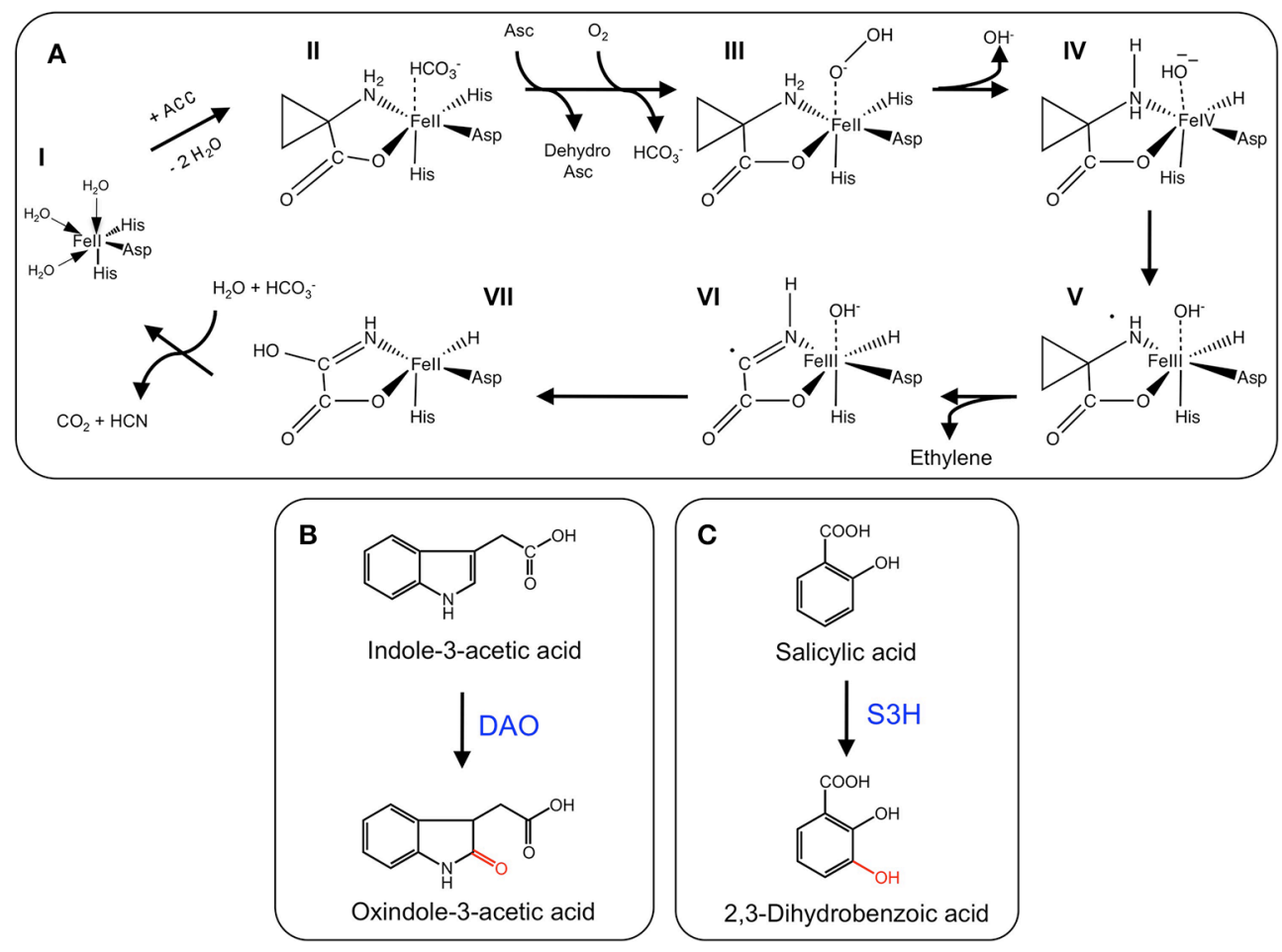

FIGURE 4 | (A) Proposed mechanism of ethylene formation by ACCO. (I) Ferrous-iron binding in the active site of the jellyroll structure. (II) Addition of ACC displaces two water molecules and permits binding. $\mathrm{CO}_{2}$ maximizes enzyme activity by reacting with a proposed metal bound solvent molecule to generate a $\mathrm{HCO}_{3}^{-}$bound species. (III) Addition of ascorbate stimulates the loss of the bound $\mathrm{HCO}_{3}^{-}$species and enhances reactivity with molecular oxygen.
Ascorbate donates two electrons to generate the ion-oxo intermediate. (IV) Loss of hydroxide (hydrolytic cleavage) and formation of the iron-oxo intermediate. (V) Hydrogen atom abstraction (IV-V), rearrangement (V-VI), and hydroxyl radical transfer (VI-VII) form the metal-bound intermediate that decomposes to $\mathrm{CO}_{2}$ and hydrogen cyanide (VII-I) (Adapted from Hausinger, 2004). (B) Oxidation of IAA by DAO. (C). Hydroxylation of salicylic acid by $\mathrm{S} 3 \mathrm{H}$. $\mathrm{S} 3 \mathrm{H}$. 
consequences on the development of male organs (Zhao et al., 2013).

\section{SALICYLIC ACID CATABOLISM}

The phenolic plant growth regulator salicylic acid (SA) is involved in several plant growth and developmental processes including plant defense, stress responses, and senescence (Zhang et al., 2013). Although SA biosynthesis is well established, SA catabolism is not well understood. Recently, the major inactive forms of SA in senescing leaves were identified as 2,3 and 2,5-dihydroxybenzoic acid sugar conjugates (2,3-DHBA and 2,5DHBA, respectively), suggesting that hydroxylation is involved in SA catabolism (Bartsch et al., 2010). The At4g10500 gene from Arabidopsis is a 2-ODD annotating as a senescence-related gene. Interestingly, At4g10500 transcripts accumulate during senescence and upon treatment with SA. Using a T-DNA insertion line, At4g10500 transcripts were abolished, which dramatically increased the rate of leaf senescence. Further characterization of the T-DNA knockout line, an over-expression line, and wild type plants revealed striking differences to the levels of active SA and derivatives. In particular, active SA levels increased dramatically in the T-DNA line compared with both over-expression and wild type lines. In contrast, the major inactive sugar catabolites of 2,3-DHBA were undetectable in the knockout line, but accumulated to approximately $200 \%$ of wild type levels in the over-expression line. These data implicate At4g10500 as the gene encoding salicylic acid 3-hydroxylase ( $\mathrm{S} 3 \mathrm{H})$, which is responsible for the inactivation of SA to 2,3-DHBA. Recombinant S3H converted SA $\left(K_{m}=58.29 \mu \mathrm{M}\right)$ to both 2,3-dihydroxybenzoic acid (2,3-DHBA) and 2,5-DHBA (Figure 4C), in support of a role for $\mathrm{S} 3 \mathrm{H}$ in the modulation of active SA levels by converting SA to 2,3-DHBA. The irreversible conversion of SA to 2,3-DHBA allows conjugation via the addition of a sugar moiety, which yields the major inactive SA in senescing leaves (Zhang et al., 2013).

\section{2-ODDs IN SECONDARY METABOLISM FLAVONOID BIOSYNTHESIS AND METABOLISM}

Flavonoids are a highly diverse class of specialized metabolites widely distributed in higher plants, and also found in liverworts and horsetails (Martens et al., 2010). Among the numerous functions assigned to flavonoids are protection from UV-B irradiation (Li et al., 1993), signaling with insects and plants (Harborne and Williams, 2000), and a general adaptation to ecological niches during periods of abiotic stress (Martens et al., 2010). Some flavonoids also exhibit pharmacological properties including sedative (Fernández et al., 2004) and anti-inflammatory effects (Williams et al., 1999; Harsteen, 2002).

Flavonoid biosynthesis begins with the amino acid phenylalanine, which undergoes deamination to trans-cinnamic acid. Subsequent oxidation of trans-cinnamic acid yields p-coumaric acid, which undergoes transformation to $p$-coumaroyl-CoA. The committed step in flavonoid biosynthesis is catalyzed by chalcone synthase, which yields chalcone via the condensation of one molecule of p-coumaroyl-CoA and three molecules of malonylCoA. Subsequent isomerization of chalcone generates the tricyclic (2S)-flavonone backbone (Shirley, 1996), which is subsequently modified via different enzymes, including glucosyltransferases,
O-methyltransferases, CYPs and 2-ODDs. These modifications lead to the diversity of flavonoids found in plants, including isofavones, flavones, flavonols, anthocyanidins, and proanthocyanidins.

Several 2-ODDs catalyze key oxidative reactions that facilitate the formation of different flavonoid subclasses (Figure 5A). Oxidation of (2S)-flavonones, by the 2-ODD flavone synthase (FNS I), introduces a double bond at C-2/C-3 to yield flavones. FNS I occurs primarily in members of the Apiaceae (Britsch, 1990; Martens et al., 2001; Gebhardt et al., 2005, 2007), but has also been reported in Oryza sativa (Lee et al., 2008) and Equisetum arvense (Bredebach et al., 2011). Alternatively, a CYP (FNS II) is thought to catalyze the same reaction in larger number of plants (Kochs and Grisebach, 1987; Akashi et al., 1999; Martens and Forkmann, 1999; Davies and Schwinn, 2007). (2S)-Flavonones are converted to dihydroflavonols by $\mathrm{C}-3$ hydroxylation, which is catalyzed by another 2-ODD, flavonone $3 \beta$-hydroxylase $(\mathrm{F} 3 \mathrm{H}$; Britsch and Grisebach, 1986; Britsch et al., 1992). The location of $\mathrm{F} 3 \mathrm{H}$ in the biosynthetic pathway has implications for the type and quantity of downstream products since it competes with FNS I and FNS II for available (2S)-flavonones (Martens et al., 2010). Dihydroflavonols serve as substrates for flavonol synthase (FLS), which competes with dihydroflavonol 4-reductase (D4R) and LDOX for the production of flavonols or anthocyanidins and proanthocyanidins, respectively. FLS and ANS are also 2-ODDs. FLS introduces a double bond at C-2/C-3 to yield flavonols (Spribille and Forkmann, 1984; Holton et al., 1993), whereas D4R selectively reduces the C-4 keto group of dihydroflavonols to form the requisite alcohol for ANS activity. ANS oxidizes this substrate, yielding anthocyanidins, or proanthocyanidins (Saito et al., 1999). Two additional 2-ODDs have been detected in saxifrage (Chrysosplenium americanum) and sweet basil (Ocimum basilicum). Flavonol 6-hydroxylase from saxifrage preferentially hydroxylates the C-6 position of trimethylquercetin to yield 6-hydroxy-trimethylquercetin (Figure 5B; Anzellotti and Ibrahim, 2004). The enzyme from sweet basil catalyzes the $O$ demethylation of gardenin $\mathrm{B}$ to nevadensin in the presence of 2-ODD co-factors and reaction conditions, however, the corresponding gene has not been isolated (Figure 5C; Berim and Gang, 2013).

\section{BENZYLISOQUINOLINE ALKALOID BIOSYNTHESIS}

Benzylisoquinoline alkaloids (BIAs) are a group of plant specialized metabolites derived from the amino acid tyrosine. The most important source of BIAs is opium poppy (Papaver somniferum), which has the exclusive ability to synthesize several medicinal compounds including the narcotic analgesics morphine and codeine, the vasodilator papaverine, the cough suppressant and potential anti-cancer drug noscapine, and the precursor to several semi-synthetic opiates thebaine. Opium poppy remains the sole commercial source for these compounds. Other BIAs include sanguinarine and magnoflorine, which are thought to function as phytoalexins (Weiss et al., 2006).

The committed step leading to BIAs is catalyzed by norcoclaurine synthase (NCS), which catalyzes the condensation of two tyrosine derivates to form the central intermediate $(S)$ norcoclaurine (Samanani et al., 2004). (S)-Norcoclaurine is 


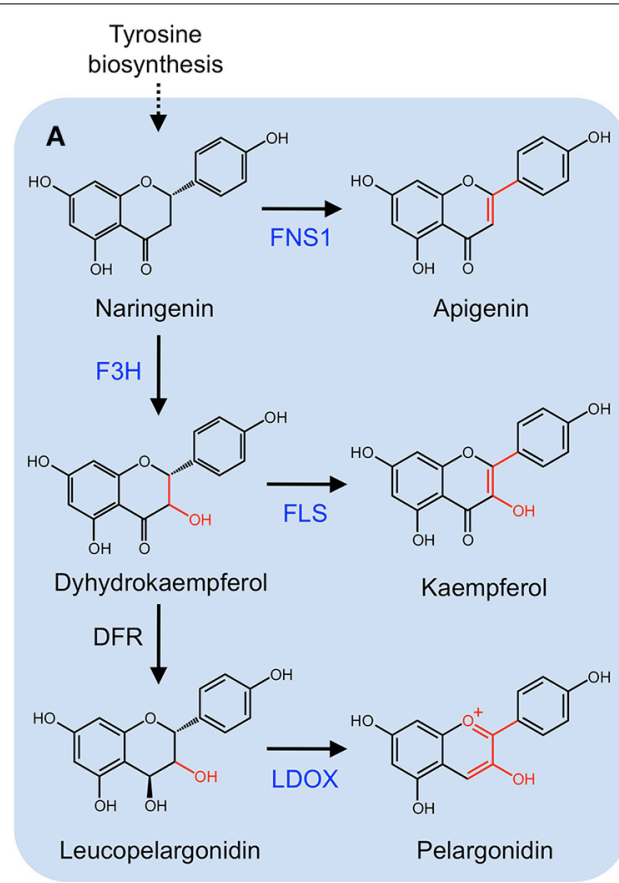

FIGURE 5 | (A) Core flavonoid metabolism. Oxidation of (2S)-flavonones by FNS I. (2S)-Flavonones can also be converted to dihydroflavonols by $\mathrm{F} 3 \mathrm{H}$. Dihydroflavonols serve as substrates for flavonol synthase (FLS), competing
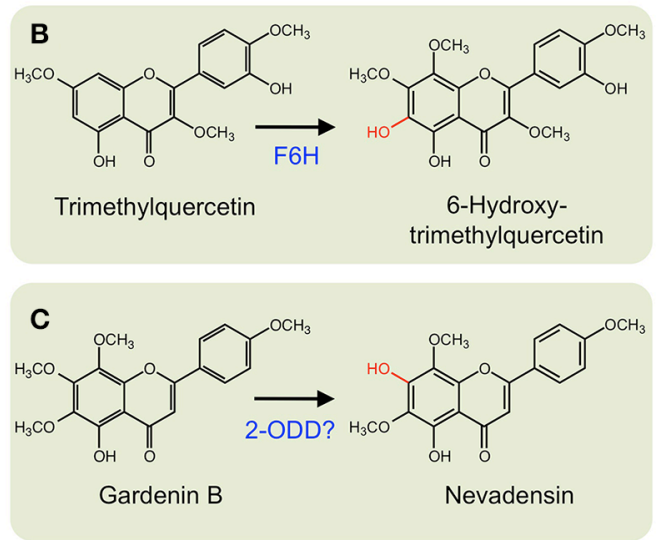

with dihydroflavonol 4-reductase (D4R) and leucoanthocyanidin synthase (LDOX). (B) 6-Hydroxy-trimethylquercetin formation by F6H. (C) $O$-Demethylation of gardenin $B$ to nevadensin. converted to the key branch-point intermediate $(S)$-reticuline, from which nearly all BIA subclasses are derived (Ziegler and Facchini, 2008). Recently, a 2-ODD-like enzyme from Coptis japonica (Minami et al., 2007) was reported to exhibit NCS activity, however, the results remain questionable (Lee and Facchini, 2010). Interestingly, this 2-ODD was not used in an engineered microbial system for the production of $(S)$-reticuline, in favor of an entirely unrelated enzyme (Nakagawa et al., 2011).

CYPs were long considered responsible for the late $O$-demethylation steps in the branch pathway converting $(S)$-reticuline to morphine in opium poppy owing to the activity of human CYP2D6, which catalyzes the reactions (Grobe et al., 2009). Using an opium poppy DNA microarray to compare the transcriptomes of high-morphine and morphine-free chemotypes, a gene encoding a 2-ODD was identified (Hagel and Facchini, 2010). The recombinant protein catalyzed the 6-Odemethylation of thebaine and oripavine, and the enzyme was named thebaine 6-O-demethylase (T6ODM) (Figure 6A). Two related 2-ODDs were identified in opium poppy. One, codeine $\mathrm{O}$-demethylase (CODM), showed strict 3-O-demethylation activity with thebaine and codeine (Hagel and Facchini, 2010).

Subsequently, broader metabolite functions were detected for T6ODM and CODM in opium poppy, and a role for the previously uncharacterized 2-ODD was determined (Farrow and Facchini, 2013). Surprisingly, T6ODM, CODM, and protopine $O$-dealkylase (PODA) catalyze the $O$-demethylation of several BIAs with $O$-linked methyl groups. Moreover, CODM, and PODA catalyze the $\mathrm{O}, \mathrm{O}$-demethylenation of protopine and/or protoberberine alkaloids (Figure 6B). The O,O-demethylenation activity is the first associated with a plant enzyme. Previously, only mammalian CYPs were shown to O,O-demethylenate certain compounds containing methylenedioxy bridges. Virus-induced gene silencing (VIGS) in opium poppy plants confirmed not only the participation of T6ODM and CODM in protopine metabolism, but unexpectedly highlighted a possible role in the regulation of sanguinarine levels (Farrow and Facchini, 2013). Sanguinarine and protopine are widely distributed in plants suggesting a possible ancestral function for 2-ODDs, from which opiate $\mathrm{O}$-demethylation evolved. Interestingly, domain-swapping of non-conserved regions of T6ODM and CODM (Runguphan et al., 2012) resulted in a mutant capable of $O$-demethylating codeine, but not thebaine (Figure 1).

\section{GLUCOSINOLATE BIOSYNTHESIS}

Glucosinolates are nitrogenous and sulfur-containing compounds found mainly in the order Brassicales and known for their pungent taste in foods such as mustard greens (Brassica juncea) and horseradish (Armoracia rusticana). Like other plant specialized metabolites, glucosinolates serve as protective agents or insect attractants. The biosynthesis of glucosinolates begins with one of three amino acid substrates, which are oxidized by CYPs to form an oxime. The introduction of a sulfur atom through aci-nitro and $S$-alkyl-thiohydroximate intermediates and subsequent addition of a glucose moiety yield the glucosinolate scaffold (Halkier and Du, 1997). Modification of the glucosinolate side chain occurs via several enzyme types, including methylthioalkylmalate synthases that control the carbon chain length of the final glucosinolate structure, a family of glucosinolate flavin 


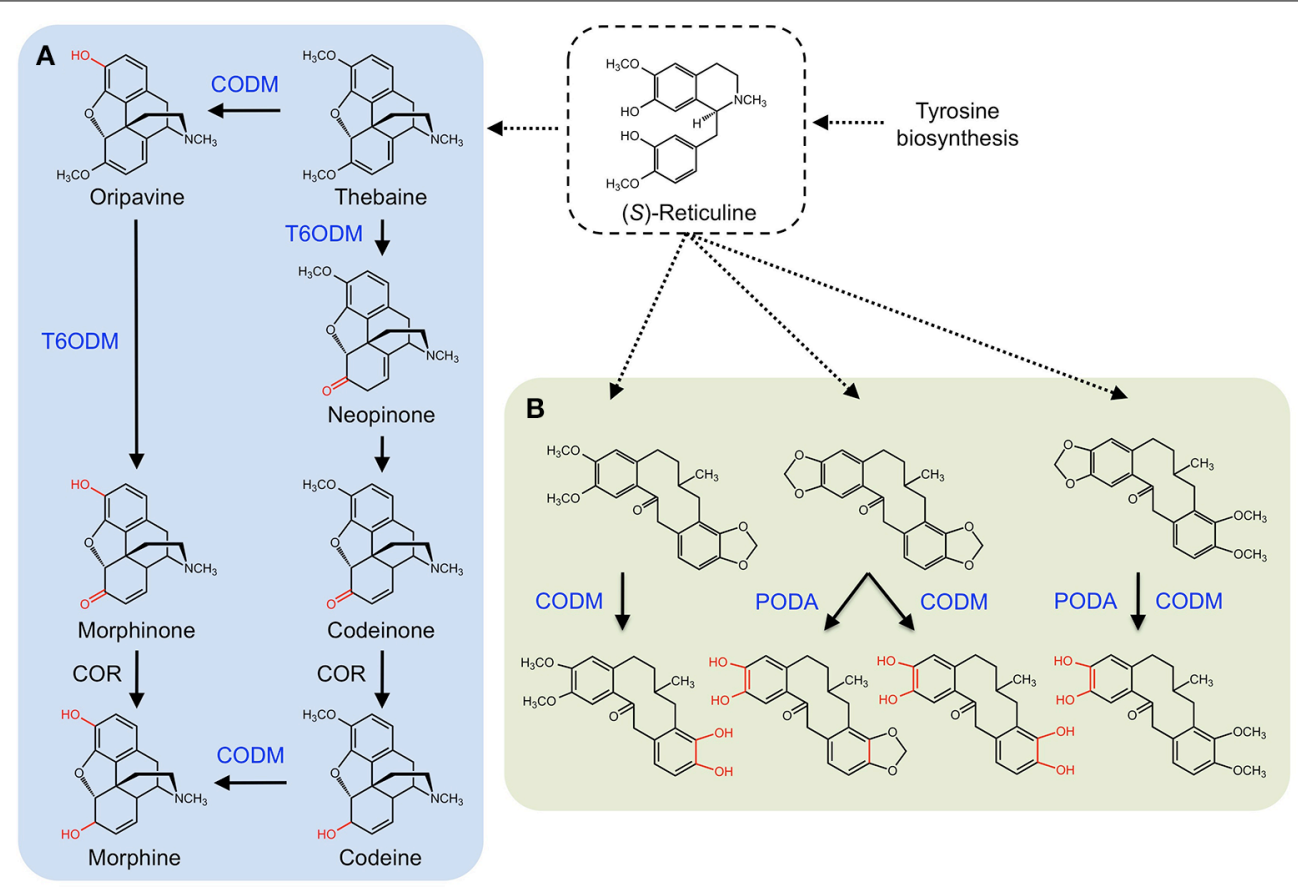

FIGURE 6 | Benzylisoquinoline alkaloid biosynthesis in Papaver somniferum. (S)-reticuline is an important branch-point intermediate leading to many alkaloids including the morphinans (A) and protopines (B). (A)
CODM and T6ODM are responsible for the O-demethylation steps leading to morphine. (B) CODM and PODA catalyze the O-demethylations and O,O-demethylenation of protopines. monooxidases that oxidize methylthioalkyl glucosinolates to their corresponding methylsulfinylalkyl derivatives, and a family of 2-ODD that modify the methylsulfinylalkyl glucosinolate side chains to alkenyl and hydroxyalkyl glucosinolates (Halkier and Du, 1997; Hansen et al., 2008). Discovery of a small gene cluster encoding 2-ODDs was achieved using a fine-scale mapping approach. Two genes encode enzymes (AOP2 and AOP3) involved in glucosinolate side chain modification. AOP2 catalyzes the conversion of 3-methylsulfinylpropyl to the allyl glucosinolate, and 4methylsulfinylbutyl to the 3-butenyl glucosinolate, whereas AOP3 catalyzes the transformation of the 3-methylsulfinylpropyl glucosinolate to 3-hydroxypropyl glucosinolate (Kliebenstein et al., 2001, Figure 7A). Recently, a third 2-ODD (GSL-OH) was discovered that operates immediately after AOP2. Specifically, GSL-OH catalyzes the 2-hydroxylation of but-3-enyl glucosinolate to 2hydroxybut-3-enyl glucosinolate (Figure 7A). Interestingly, GSL$\mathrm{OH}$ was apparently recruited from a different 2-ODD clade, and yields a reaction product that is more toxic to pests than upstream intermediates. Additionally, 2-hydroxybut-3-enyl glucosinolate is a major source of bitter flavor in cruciferous vegetables. Tissue disruption causes hydrolysis of 2-hydroxybut-3-enyl glucosinolate to a goitrin, which precludes the use of cruciferous crops as a cattle feed. In contrast, conversion of 2-hydroxybut-3-enyl glucosinolate to a nitrile yields a compound that stimulates antioxidant pathways in humans (Hansen et al., 2008).

\section{TROPANE ALKALOID BIOSYNTHESIS}

The tropane alkaloids (TAs) occur mainly in the Solanaceae family, but are scattered throughout other plant species (Jirschitzka

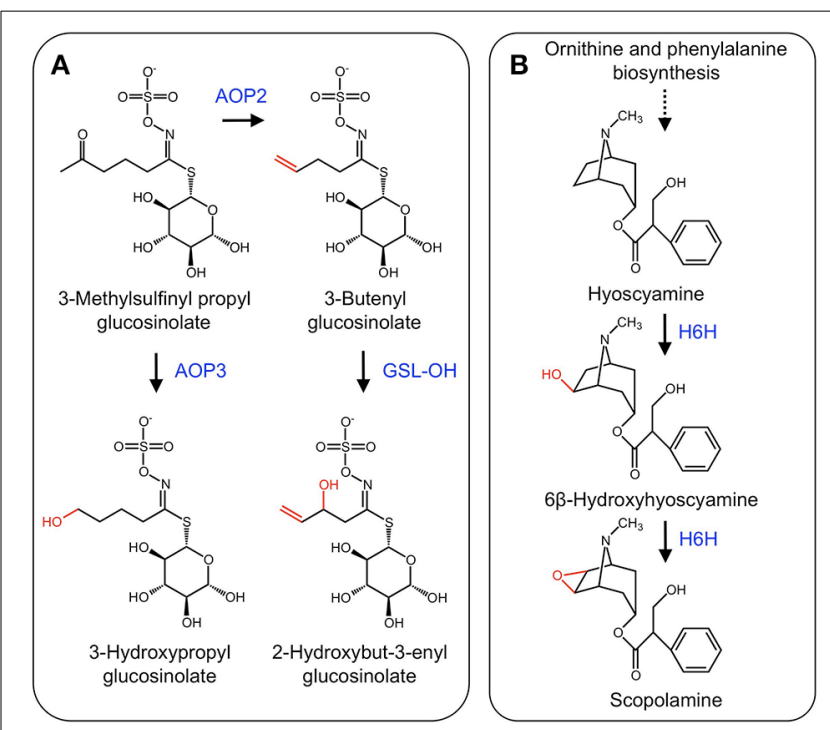

FIGURE 7 | (A) Side-chain modification of glucosinolates catalyzed by AOP2, AOP3, and GSL-OH. (B) Hydroxylation of hyoscyamine to $6 \beta$-hydroxyhyoscyamine and subsequent epoxidation to scopolamine by $\mathrm{H} 6 \mathrm{H}$.

et al., 2012). TAs are a hallucinogenic and toxic group of plant specialized metabolites, the most notorious of which is cocaine (Docimo et al., 2012). Hyoscyamine and scopolamine that are the two most pervasive TAs and are used for the treatment of several ailments (Li et al., 2012). TA biosynthesis begins with 
the amino acids L-ornithine or L-arginine, which are converted to putrescine. Several other conversions leading to hyoscyamine have been elucidated (Ziegler and Facchini, 2008). The final twostep conversion of hyoscyamine to the 6,7-epoxide scopolamine is catalyzed by the 2-ODD hyoscyamine $6 \beta$-hydroxylase $(\mathrm{H} 6 \mathrm{H})$ (Figure 7B) (Hashimoto and Yamada, 1986, 1987). Genes encoding $\mathrm{H} 6 \mathrm{H}$ have been isolated from several solanaceous plants including Atropa belladonna (Li et al., 2012), Hyoscyamus niger (Matsuda et al., 1991), Atropa baetica (El Jaber-Vazdekis et al., 2009), Anisodus acutangulus (Kai et al., 2007), Anisodus tanguticus (Liu et al., 2005), and Datura metel L. (Pramod et al., 2010).

\section{MONOTERPENE INDOLE ALKALOID BIOSYNTHESIS}

The monoterpene indole alkaloids (MIAs) are a class of plant specialized metabolites found mainly in members of the Apocynaceae, Loganiaceae, and Rubiaceae families. Several MIAs are medicinally important including the anticancer agents vinblastine, vincristine, and camptothecin, the anti-malarial drug quinine, and the antihypertensive compound ajmalicine (De Luca et al., 2014). In the biosynthetic pathway leading to vinblastine, vindoline is one of the monomeric components of the active dimer. The biosynthesis of vindoline in Catharanthus roseus involves the hydroxylation of desacetoxyvindoline to the immediate precursor of vindoline, deacetoxyvindoline, by the 2-ODD desdeoxyvindoline 4-hydroxylase (D4H) (Figure 8A; De Carolis et al., 1990; De Carolis and De Luca, 1993; Vazquez-Flota et al., 1997).

\section{BENZOXAZINOID BIOSYNTHESIS}

Benzoxazinoids such as DIBOA and DIMBOA are allelophatic compounds mostly found in members of the Poaceae family, which includes maize (Zea mays), wheat (Triticum aestivum), and rye (Secale cereale) (Dick et al., 2012). Benzoxazinoids in grasses are derived from tryptophan and a number of enzyme types are involved in DIMBOA biosynthesis, including an indole3-glycerol phosphate lyase, CYPs, an UDP-glycosyl transferase, an O-methyltransferase, and a 2-ODD. In maize, DIBOAglucoside is hydroxylated into TRIBOA-glucoside by the 2-ODD BENZOXAZINLESS6 (BX6) (Figure 8B; Frey et al., 2003). BX6 was implicated by treating maize seedlings with the 2-ODD inhibitor prohexadion-Ca, which reduced the accumulation of DIMBOA. Diagnostic sequence motifs of known 2-ODDs showed that BX6 was part of a DIBOA gene cluster. Transposon insertional mutants of BX6 markedly reduced DIMBOA biosynthesis. Subsequent biochemical analyses confirmed the activity and specificity of BX6 for DIBOA-glucoside (Jonczyk et al., 2008).

\section{COUMARIN BIOSYNTHESIS}

Coumarins are a group of common plant defense compounds derived from phenylpropanoid metabolism, partially following the pathway to lignin biosynthesis. The branch point involves

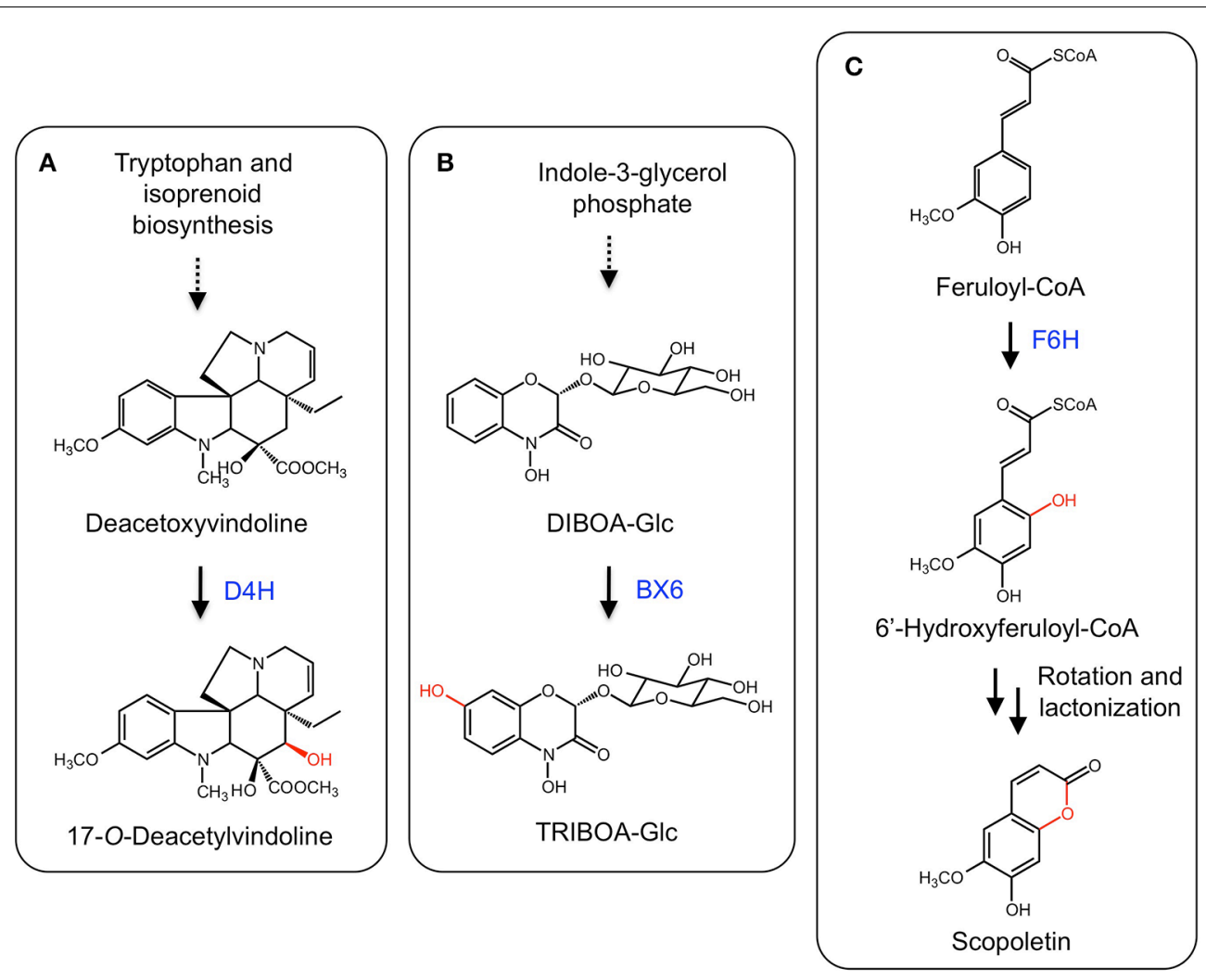

FIGURE 8 | (A) Hydroxylation of deacetoxyvindoline by D4H leading to 17-O-deacetylvindoline. (B) B6X hydroxylates DIBOA-GIC to form TRIBOA-GIc. (C) Hydroxylation of feruoyl-CoA by F6H yielding scopoletin via spontaneous rotation and lactonization. 
the ortho-hydroxylation of cinnamates, which is critical for subsequent trans-cis isomerization and lactonization reactions completing the formation of the core $2 \mathrm{H}$-1-benzopyran-2-one structure of coumarins. The ortho-hydroxylation of cinnamates was presumed to be catalyzed by a CYP based on the occurence of enzyme activity in chloroplastic fractions (Gestetner and Conn, 1974; Kai et al., 2008). However, a T-DNA mutation of an Arabidopsis gene $\left(F 6^{\prime} H 1\right)$ encoding a 2-ODD reduced scopoletin levels in roots. Two recombinant enzymes $\left(\mathrm{F}^{\prime} \mathrm{H} 1\right.$ and $\mathrm{F}^{\prime} \mathrm{H} 2$ ) exhibited ortho-hydroxylation activity with relative specificity for feruloyl-CoA (Figure 8C). Whereas $F 6^{\prime} H 1$ was expressed, $F 6^{\prime} \mathrm{H} 2$ transcript levels were low and a corresponding T-DNA mutant did not affect scopoletin accumulation (Kai et al., 2008). Similar 2-ODDs have been discovered from sweet potato (Ipomoea batatas; Matsumoto et al., 2012) and common rue (Ruta graveolens; Vialart et al., 2012). One sweet potato enzyme catalyzed the ortho-hydroxylation of feruoyl CoA, whereas a second from sweet potato and the common rue enzyme catalyzed the ortho-hydroxylation of $p$-coumaryl-CoA and feruoyl-CoA. The $2^{\prime}$-hydroxylase activity on $p$-comaryl CoA yields umbelliferone.

\section{MUGINEIC ACID BIOSYNTHESIS}

In response to iron deficiency, graminaceous plants such as barley (Hordeum vulgare) and rye (Secale cereale) synthesize mugineic acid phytosiderophores to chelate iron from the soil. Mugineic acid biosynthesis begins with the conversion of $S$-adenosyl- $L$-methionine to $2^{\prime}$-deoxymugineic acid via nicotianamine synthase, nicotianamine aminotransferase, and a reductase. 2'-Deoxymugineic oxidation by two 2-ODDs, IDS2 and IDS3, yields 3-epi-hydroxy-deoxy mugineic acid and mugineic acid, respectively. Further oxidation of these compounds by the same enzymes yield epi-hydroxymugineic acid (Figure 9A) (Nakanishi et al., 1993, 2000; Okumura et al., 1994).

\section{STEROIDAL GLYCOALKALOID BIOSYNTHESIS}

Steroidal glycoalkaloids (SGs) are produced in solanaceous plants such as potato (Solanum tuberosum) and tomato (Solanum lycopersicum), and have negative health effects on humans. Several SG biosynthetic genes are clustered in the potato and tomato genomes, with others found on a duplicated region (Itkin et al., 2013). A gene encoding a 2-ODD, GAME11, occurs in the cluster and has been associated with steroidal glycoalkaloid biosynthesis. Using VIGS, suppression of GAME11 resulted in a substantial decrease in $\alpha$-tomatine and an increase in steroidal saponins suggesting that GAME11 competes for substrate with saponin biosynthetic enzymes. Currently, GAME11 is thought to hydroxylate 22,26-dihydroxycholesterol and assist in ring closure (Figure 9B). Interestingly, silencing GAME4 led to a dramatic decrease in $\alpha$-tomatine in both potato tubers and tomato fruit without pleiotropic effects, providing a means to eliminate these anti-nutritional compounds (Itkin et al., 2013).

\section{EVOLUTION OF 2-OXOGLUTARATE/Fe(II)-DEPENDENT DIOXYGENASES}

Analysis of 2-ODDs from green algae to angiosperms provided an interesting perspective on the evolution of plant 2-ODDs (Kawai
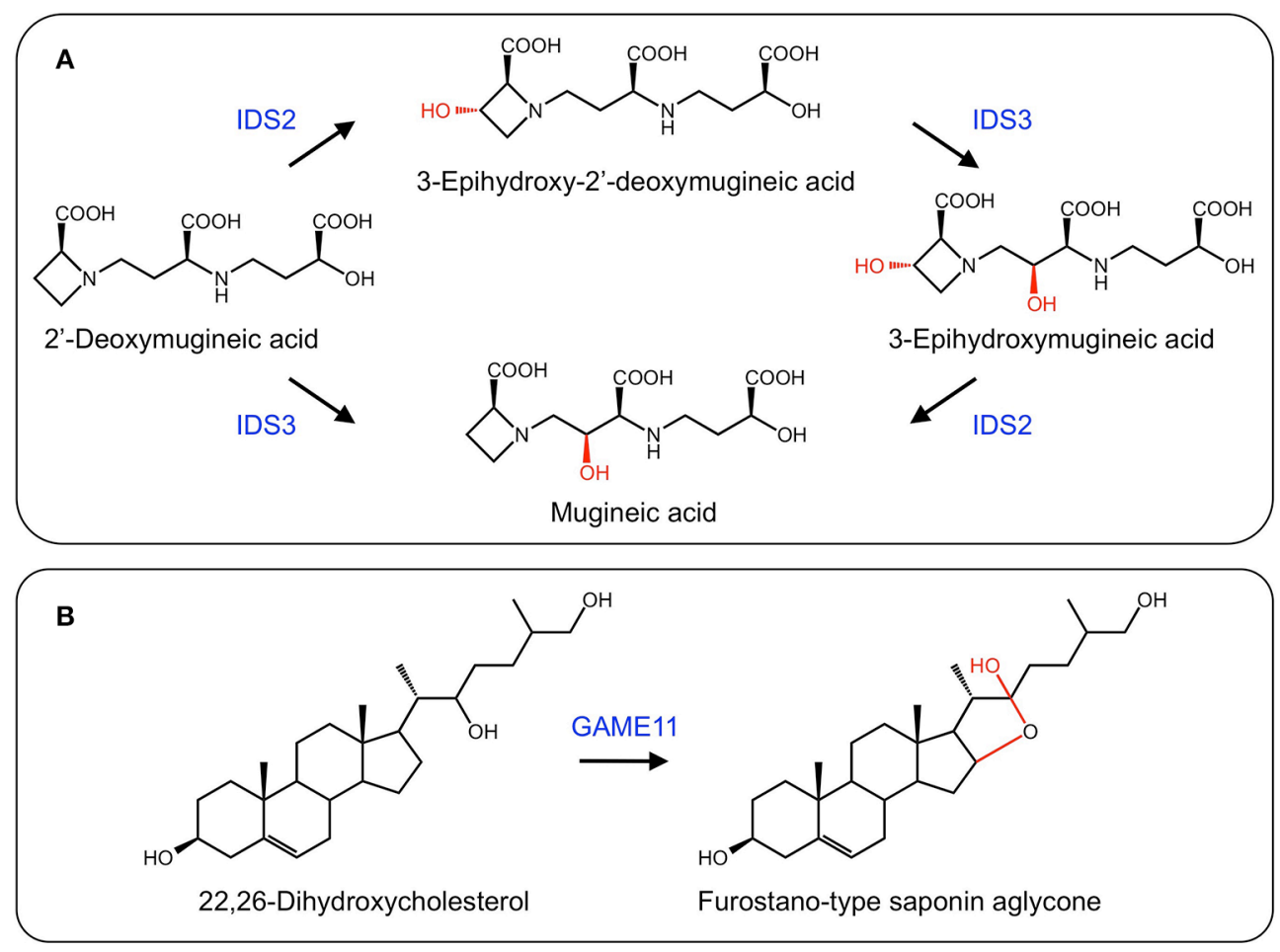

FIGURE 9 | (A) Formation of iron scavenging mugineic acids by IDS2 and IDS3 (Nakanishi et al., 2000). (B) Proposed activity of GAME11 in steroidal glycoalkaloid biosynthesis. 
et al., 2014). The conservation of genes responsible for DNA repair $(\mathrm{AlkB})$, post-translational modification $(\mathrm{P} 4 \mathrm{H})$, and control of epigenetics (Jmj) across all taxa is attributed to essential roles in core metabolism. Such functionally diverse enzymes occur in distinct phylogenetic clades. Exceptional functional diversity is also evident among 2-ODDs involved in higher plant specialized metabolism, which also form a separate phylogenetic clade. Algae exhibit the fewest 2-ODDs involved in specialized metabolism and the number increases along evolutionary lines bryophytes to angiosperms. As a result of new environmental stresses associated with the migration to land, extensive duplication and functional diversification of genes encoding 2-ODDs allowed the formation of many new specialized metabolites (Kawai et al., 2014).

\section{CONCLUSIONS}

We have highlighted the diversity of conversions catalyzed by $2-O D D s$ in plant metabolism. In primary metabolism, 2ODDs have established roles in DNA repair, epigenetics, posttranslational modification, and plant growth regulator activation and catabolism. In specialized metabolism, 2-ODDs participate in numerous pathways, and display as much functional diversity as CYPs.

\section{REFERENCES}

Akashi, T., Fukuchi-Mizutani, M., Aoki, T., Ueyama, Y., Yonekura-Sakakibara, K., Tanaka, Y., et al. (1999). Molecular cloning and biochemical characterization of a novel cytochrome P450, flavone synthase II, that catalyzes direct conversion of flavanones to flavones. Plant Cell Physiol. 40, 1182-1186. doi: 10.1093/oxfordjournals.pcp.a029505

Anzellotti, D., and Ibrahim, R. K. (2004). Molecular characterization and functional expression of flavonol 6-hydroxylase. BMC Plant Biol. 4:20. doi: 10.1186/1471-2229-4-20

Bartsch, M., Bednarek, P., Vivancos, P. D., Schneider, B., von Roepenack-Lahaye, E., Foyer, C. H., et al. (2010). Accumulation of isochorismate-derived 2,3dihydroxybenzoic 3-O-b-D-xyloside in Arabidopsis resistance to pathogens and ageing of leaves. J. Biol. Chem. 285, 25654-25665. doi: 10.1074/jbc.M109.092569

Berim, A., and Gang, D. R. (2013). The roles of a flavone-6-hydroxylase and 7-Odemethylation in the flavone biosynthetic network of sweet basil. J. Biol. Chem. 288, 1795-1805. doi: 10.1074/jbc.M112.420448

Bredebach, M., Matern, U., and Martens, S. (2011). Three 2-oxoglutaratedependent dioxygenase activities of Equisetum arvense L. forming flavone and flavonol from (2S)-naringenin. Phytochemistry 72, 557-563. doi: 10.1016/j. phytochem.2011.01.036

Britsch, L. (1990). Purification and characterization of flavone synthase I, a 2oxoglutarate-dependent desaturase. Arch. Biochem. Biophys. 282, 152-160. doi: 10.1016/0003-9861(90)90099-K

Britsch, L., and Grisebach, H. (1986). Purification and characterization of (2S)flavanone 3-hydroxylase from Petunia hybrida. Eur. J. Biochem. 156, 569-577. doi: 10.1111/j.1432-1033.1986.tb09616.x

Britsch, L., Ruhnau-Brich, B., and Forkmann, G. (1992). Molecular cloning, sequence analysis, and in vitro expression of flavanone 3 beta-hydroxylase from Petunia hybrida. J. Biol. Chem. 267, 5380-5387.

Charron, J.-B. F., He, H., Elling, A. A., and Deng, X. W. (2009). Dynamic landscapes of four histone modifications during deetiolation in Arabidopsis. Plant Cell 21, 3732-3748. doi: 10.1105/tpc.109.066845

Chen, Q., Chen, X., Wang, Q., Zhang, F., Lou, Z., Zhang, Q., et al. (2013). Structural basis of a histone $\mathrm{H} 3$ lysine 4 demethylase required for stem elongation in rice. PLoS Genet. 9:e1003239. doi: 10.1371/journal.pgen.1003239

Chen, X., Hu, Y., and Zhou, D.-X. (2011). Epigenetic gene regulation by plant Jumonji group of histone demethylase. Biochim. Biophys. Acta 1809, 421-426. doi: 10.1016/j.bbagrm.2011.03.004

Chiang, H. H., Hwang, I., and Goodman, H. M. (1995). Isolation of the Arabidopsis GA4 locus. Plant Cell 7, 195-201. doi: 10.1105/tpc.7.2.195
Cho, J.-N., Ryu, J.-Y., Jeong, Y.-M., Park, J., Song, J.-J., Amasino, R. M., et al. (2012). Control of seed germination by light-induced histone arginine demethylation activity. Dev. Cell 22, 736-748. doi: 10.1016/j.devcel.2012.01.024

Clifton, I. J., McDonough, M. A., Ehrismann, D., Kershaw, N. J., Granatino, N., and Schofield, C. J. (2006). Structural studies on 2-oxoglutarate oxygenases and related double-stranded beta-helix fold proteins. J. Inorg. Biochem. 100, 644-669. doi: 10.1016/j.jinorgbio.2006.01.024

Davies, K. M., and Schwinn, K. E. (2007). "Molecular biology and biotechnology of flavonoid biosynthesis," in Flavonoids - Chemistry, Biochemistry and Applications eds Ø. M. Andersen, and K. R. Markham (Boca Raton, FL: CRC Press), 143-218.

De Carolis, E., Chan, F., Balsevich, J., and De Luca, V. (1990). Isolation and Characterization of a 2-oxoglutarate dependent dioxygenase involved in the second-to-last step in vindoline biosynthesis. Plant Physiol. 94, 1323-1329. doi: 10.1104/pp.94.3.1323

De Carolis, E., and De Luca, V. (1993). Purification, characterization, and kinetic analysis of a 2-oxoglutarate-dependent dioxygenase involved in vindoline biosynthesis from Catharanthus roseus. J. Biol. Chem. 268, 5504-5511.

De Carolis, E., and De Luca, V. (1994). 2-Oxoglutarate-dependent dioxygenase and related enzymes: biochemical characterization. Phytochemistry 36, 1093-1107. doi: 10.1016/S0031-9422(00)89621-1

De Luca, V., Salim, V., Thamm, A., Masada, S. A., and Yu, F. (2014). Making iridoids/secoiridoids and monoterpenoid indole alkaloids: progress on pathway elucidation. Curr. Opin. Plant Biol. 19, 35-42. doi: 10.1016/j.pbi.2014.03.006

Dick, R., Rattei, T., Haslbeck, M., Schwab, W., Gierl, A., and Frey, M. (2012). Comparative analysis of benzoxazinoid biosynthesis in monocots and dicots: independent recruitment of stabilization and activation functions. Plant Cell 24, 915-928. doi: 10.1105/tpc.112.096461

Docimo, T., Reichelt, M., Schneider, B., Kai, M., Kunert, G., Gershenzon, J., et al. (2012). The first step in the biosynthesis of cocaine in Erythroxylum coca: the characterization of arginine and ornithine decarboxylases. Plant Mol. Biol. 78, 599-615. doi: 10.1007/s11103-012-9886-1

Drabløs, F., Feyzi, E., Aas, P. A., Vaagbø, C. B., Kavli, B., Bratlie, M. S., et al. (2004). Alkylation damage in DNA and RNA-repair mechanisms and medical significance. DNA Repair (Amst.) 3, 1389-1407. doi: 10.1016/j.dnarep.2004.05.004

El Jaber-Vazdekis, N., González, C., Ravelo, A. G., and Zárate, R. (2009). Cloning, characterization and analysis of expression profiles of a cDNA encoding a hyoscyamine 6b-hydroxylase (H6H) from Atropa baetica Willk. Plant Physiol. Biochem. 47, 20-25. doi: 10.1016/j.plaphy.2008.09.004

Farrow, S. C., and Facchini, P. J. (2013). Dioxygenases catalyze O-demethylation and $\mathrm{O}, \mathrm{O}$-demethylenation with widespread roles in benzylisoquinoline alkaloid metabolism in opium poppy. J. Biol. Chem. 288, 28997-29012. doi: 10.1074/jbc.M113.488585

Fernández, S., Wasowski, C., Paladini, A. C., and Marder, M. (2004). Sedative and sleep-enhancing properties of linarin, a flavonoid-isolated from Valeriana officinalis. Pharmacol. Biochem. Behav. 77, 399-404. doi: 10.1016/j.pbb.2003.12.003

Flashman, E., and Schofield, C. J. (2007). The most versatile of all reactive intermediates? Nat. Chem. Biol. 3, 86-87. doi: 10.1038/nchembio 0207-86

Frey, M., Huber, K., Park, W. J., Sicker, D., Lindberg, P., Meeley, R. B., et al. (2003). A 2-oxoglutarate-dependent dioxygenase is integrated in DIMBOA-biosynthesis. Phytochemistry 62, 371-376. doi: 10.1016/S0031-9422(02)00556-3

Gebhardt, Y. H., Witte, S., Steuber, H., Matern, U., and Martens, S. (2007). Evolution of flavone synthase I from parsley flavanone 3b-hydroxylase by site-directed mutagenesis. Plant Physiol. 144, 1442-1454. doi: 10.1104/pp.107. 098392

Gebhardt, Y., Witte, S., Forkmann, G., Lukacin, R., Matern, U., and Martens, S. (2005). Molecular evolution of flavonoid dioxygenases in the family Apiaceae. Phytochemistry 66, 1273-1284. doi: 10.1016/j.phytochem.2005.03.030

Gestetner, B., and Conn, E. E. (1974). The 2-hydroxylation of trans-cinnamic acid by chloroplasts from Melilotus alba Desr. Arch. Biochem. Biophys. 163, 617-624. doi: 10.1016/0003-9861(74)90522-0

Gorres, K. L., and Raines, T. (2010). Prolyl 4-hydroxylase. Crit. Rev. Biochem. Mol. Biol. 45, 106-124. doi: 10.3109/10409231003627991

Grobe, N., Zhang, B., Fisinger, U., Kutchan, T. M., Zenk, M. H., and Guengerich, F. P. (2009). Mammalian cytochrome P450 enzymes catalyze the phenol-coupling step in endogenous morphine biosynthesis. J. Biol. Chem. 284, 24425-24431. doi: $10.1074 /$ jbc.M109.011320

Groves, J. T. (2006). High-valent iron in chemical and biological oxidations. J. Inorg. Biochem. 100, 434-447. doi: 10.1016/j.jinorgbio.2006.01.012 
Hagel, J. M., and Facchini, P. J. (2010). Biochemistry and occurrence of odemethylation in plant metabolism. Front. Physiol. 1:14. doi: 10.3389/fphys. 2010.00014

Halkier, B. A., and Du, L. (1997). The biosynthesis of glucosinolates. Trends Plant Sci. 2, 425-431. doi: 10.1016/S1360-1385(97)90026-1

Hangasky, J. A., Taabazuing, C. Y., Valliere, M. A., and Knapp, M. J. (2013). Imposing function down a (cupin)-barrel: secondary structure and metal stereochemistry in the $\alpha$ KG-dependent oxygenases. Metallomics 5, 287-301. doi: $10.1039 / \mathrm{c} 3 \mathrm{mt} 20153 \mathrm{~h}$

Hansen, B. G., Kerwin, R. E., Ober, J. A., Lambrix, V. M., Mitchell-Olds, T., Gershenzon, J., et al. (2008). A novel 2-oxoacid-dependent dioxygenase involved in the formation of the goiterogenic 2-hydroxybut-3-enyl glucosinolate and generalist insect resistance in Arabidopsis. Plant Physiol. 148, 2096-2108. doi: 10.1104/pp.108.129981

Harborne, J. B., and Williams, C. A. (2000). Advances in flavonoid research since 1992. Phytochemistry 55, 481-504. doi: 10.1016/S0031-9422(00)00235-1

Harsteen, B. H. (2002). The biochemistry and medical significance of the flavonoids. Pharmacol. Therapeut. 96, 67-202. doi: 10.1016/S0163-7258(02) 00298-X

Hashimoto, T., and Yamada, Y. (1986). Hyoscyamine 6b-hydroxylase, a 2oxoglutarate-dependent dioxygenase, in alkaloid-producing root cultures. Plant Physiol. 81, 619-625. doi: 10.1104/pp.81.2.619

Hashimoto, T., and Yamada, Y. (1987). Purification and characterization of hyoscyamine 6b-hydroxylase from root cultures of Hyoscyamus niger L. Hydroxylase and epoxidase activities in the enzyme preparation. Eur. J. Biochem. 164, 277-285. doi: 10.1111/j.1432-1033.1987.tb11055.x

Hausinger, R. P. (2004). Fe(II)/a-Ketoglutarate-dependent hydroxylases and related enzymes. Crit. Rev. Biochem. Mol. Biol. 39, 21-68. doi: 10.1080/104092304 90440541

Hayaishi, O., and Hashimoto, K. (1950). Pyrocatecase a new enzyme catalizing oxidative breakdown of pyrocatechin. J. Biochem. 37, 371-374.

Hayaishi, O., Shimazono, H., Katagiri, M., and Saito, Y. (1956). Enzymatic formation of oxalate and acetate from oxaloacetate. J. Am. Chem. Soc. 78, 5126-5127. doi: 10.1021/ja01600a084

Hedden, P., Phillips, A. L., Rojas, M. C., Carrera, E., and Tudzynski, B. (2002). Gibberellin biosynthesis in plants and fungi: a case of convergent evolution? J. Plant Growth Regul. 20, 319-331. doi: 10.1007/s003440010037

Hieta, R., and Myllyharju, J. (2002). Cloning and characterization of a low molecular weight prolyl 4-hydroxylase from Arabidopsis thaliana. Effective hydroxylation of proline-rich, collagen-like, and hypoxia-inducible transcription factor alpha-like peptides. J. Biol. Chem. 277, 23965-23971. doi: 10.1074/jbc.M201865200

Holton, T. A., Brugliera, F., and Tanaka, Y. (1993). Cloning and expression of flavonol synthase from Petunia hybrida. Plant J. 4, 1003-1010. doi: 10.1046/j. 1365-313X.1993.04061003.x

Hutton, J. J., Tappel, A. L., and Udenfriend, S. (1967). Cofactor and substrate requirements of collagen proline hydroxylase. Arch. Biochem. Biophys. 118, 231-240. doi: 10.1016/0003-9861(67)90302-5

Itkin, M., Heinig, U., Tzfadia, O., Bhide, A. J., Shinde, B., Cardenas, P. D., et al. (2013). Biosynthesis of antinutritional alkaloids in solanaceous crops is mediated by clustered genes. Science 341, 175-179. doi: 10.1126/science. 1240230

Jeong, J.-H., Song, H.-R., Ko, J.-H., Jeong, Y.-M., Kwon, Y. E., Seol, J. H., et al. (2009). Repression of FLOWERING LOCUS T chromatin by functionally redundant histone $\mathrm{H} 3$ lysine 4-demethylases in Arabidopsis. PLoS One 4:e8033. doi: 10.1371/journal.pone.0008033

Jin, C. W., You, G. Y., He, Y. F., Tang, C., Wu, P., and Zheng, S. J. (2007). Iron deficiency-induced secretion of phenolics facilitates the reutilization of root apoplastic iron in red clover. Plant Physiol. 144, 278-285. doi: 10.1104/pp.107. 095794

Jirschitzka, J., Schmidt, G. W., Reichelt, M., Schneider, B., Gershenzon, J., and D'Auria, J. C. (2012). Plant tropane alkaloid biosynthesis evolved independently in the Solanaceae and Erythroxylaceae. Proc. Natl. Acad. Sci. U.S.A. 109, 10304-10309. doi: 10.1073/pnas.1200473109

Jonczyk, R., Schmidt, H., Osterrieder, A., Fiesselmann, A., Schullehner, K., Haslbeck, M., et al. (2008). Elucidation of the final reactions of DIMBOAglucoside biosynthesis in maize: characterization of Bx6 and Bx7. Plant Physiol. 146, 1053-1063. doi: 10.1104/pp.107.111237

Jones, M. A., Covington, M. F., DiTacchio, L., Vollmers, C., Panda, S., and Harmer, S. L. (2010). Jumonji domain protein JMJD5 functions in both the plant and human circadian systems. Proc. Natl. Acad. Sci. U.S.A. 107, 21623-21628. doi: 10.1073/pnas. 1014204108

Kai, G., Chen, J., Li, L., Zhou, G., Zhou, L., Zhang, L., et al. (2007). Molecular cloning and characterization of a new cDNA encoding hyoscyamine 6betahydroxylase from roots of Anisodus acutangulus. J. Biochem. Mol. Biol. 40, 715-722. doi: 10.5483/BMBRep.2007.40.5.715

Kai, K., Mizutani, M., Kawamura, N., Yamamoto, R., Tamai, M., Yamaguchi, H., et al. (2008). Scopoletin is biosynthesized via ortho-hydroxylation of feruloyl CoA by a 2-oxoglutarate-dependent dioxygenase in Arabidopsis thaliana. Plant J. 55, 989-999. doi: 10.1111/j.1365-313X.2008.03568.x

Kawai, Y., Ono, E., and Mizutani, M. (2014). Evolution and diversity of the 2oxoglutarate-dependent dioxygenase superfamily in plants. Plant J. 78, 328-343. doi: $10.1111 /$ tpj.12479

Kende, H. (1993). Ethylene biosynthesis. Annu. Rev. Plant Physiol. Plant Mol. Biol. 44, 283-307. doi: 10.1146/annurev.pp.44.060193.001435

Kliebenstein, D. J., Lambrix, V. M., Reichelt, M., Gershenzon, J., and MitchellOlds, T. (2001). Gene duplication in the diversification of secondary metabolism: tandem 2-oxoglutarate-dependent dioxygenases control glucosinolate biosynthesis in Arabidopsis. Plant Cell 13, 681-693. doi: 10.1105/tpc.13. 3.681

Kobayashi, T., Nakanishi, H., Takahashi, M., Kawasaki, S., Nishizawa, N. K., and Mori, S. (2001). In vivo evidence that Ids3 from Hordeum vulgare encodes a dioxygenase that converts $2^{\prime}$-deoxymugineic acid to mugineic acid in transgenic rice. Planta 212, 864-871. doi: 10.1007/s004250000453

Kochs, G., and Grisebach, H. (1987). Induction and characterization of NADPHdependent flavone synthase from cell cultures of soybean. Z. Naturforsh. 42C, 343-348.

Lan, P., Li, W., Wen, T.-N., Shiau, J.-Y., Wu, Y.-C., Lin, W., et al. (2011). iTRAQ protein profile analysis of Arabidopsis roots reveals new aspects critical for iron homeostasis. Plant Physiol. 155, 821-834. doi: 10.1104/pp.110. 169508

Lange, T. (1997). Cloning gibberellin dioxygenase genes from pumpkin endosperm by heterologous expression of enzyme activities in Escherichia coli. Proc. Natl. Acad. Sci. U.S.A. 94, 6553-6558. doi: 10.1073/pnas.94.12.6553

Lange, T., Hedden, P., and Graebe, J. E. (1994a). Expression cloning of a gibberellin 20-oxidase, a multifunctional enzyme involved in gibberellin biosynthesis. Proc. Natl. Acad. Sci. U.S.A. 91, 8552-8556.

Lange, T., Robatzek, S., and Frisse, A. (1997). Cloning and expression of a gibberellin 2b,3b-hydroxylase cDNA from pumpkin endosperm. Plant Cell 9, 1459-1467.

Lange, T., Schweimer, A., Ward, D., Hedden, P., and Graebe, J. (1994b). Separation and characterisation of three 2-oxoglutarate-dependent dioxygenases from Cucurbita maxima L. endosperm involved in gibberellin biosynthesis. Planta 195, 98-107.

Lee, D. J., and Zeevaart, J. A. D. (2005). Molecular cloning of GA 2-oxidase 3 from spinach and its ectopic expression in Nicotiana sylvestris. Plant Physiol. 138, 243-254. doi: 10.1104/pp.104.056499

Lee, E.-J., and Facchini, P. (2010). Norcoclaurine synthase is a member of the pathogenesis-related 10/Bet v1 protein family. Plant Cell 22, 3489-3503. doi: 10.1105/tpc. 110.077958

Lee, Y. J., Kim, J. H., Kim, B. G., Lim, Y., and Ahn, J.-H. (2008). Characterization of flavone synthase I from rice. BMB Rep. 41, 68-71. doi: 10.5483/BMBRep.2008. 41.1.068

Li, J., Ou-Lee, T. M., Raba, R., Amundson, R. G., and Last, R. L. (1993). Arabidopsis flavonoid mutants are hypersensitive to UV-B irradiation. Plant Cell 5, 171-179. doi: $10.1105 /$ tpc.5.2.171

Li, J., van Belkum, M. J., and Vederas, J. C. (2012). Functional characterization of recombinant hyoscyamine $6 \beta$-hydroxylase from Atropa belladonna. Bioorg. Med. Chem. 20, 4356-4363. doi: 10.1016/j.bmc.2012.05.042

Lindahl, T., Sedgwick, B., Sekiguchi, M., and Nakabeppu, Y. (1988). Regulation and expression of the adaptive response to alkylating agents. Annu. Rev. Biochem. 57, 133-157. doi: 10.1146/annurev.bi.57.070188.001025

Liu, T., Zhu, P., Chen, K. D., Meng, C., and He, X. X. (2005). Molecular cloning, expression and characterization of hyoscyamine 6b-hydroxylase from hairy roots of Anisodus tanguticus. Plant Med. 71, 249-253. doi: 10.1055/s-2005837825

Loenarz, C., and Schofield, C. J. (2008). Expanding chemical biology of 2oxoglutarate oxygenases. Nat. Chem. Biol. 4, 152-156. doi: 10.1038/nchembio 0308-152 
Lu, F., Cui, X., Zhang, S., Liu, C., and Cao, X. (2010). JMJ14 is an H3K4 demethylase regulating flowering time in Arabidopsis. Cell Res. 20, 387-390. doi: $10.1038 / \mathrm{cr} .2010 .27$

Lu, S. X., Knowles, S. M., Webb, C. J., Celaya, R. B., Cha, C., Siu, J. P., et al. (2011). The Jumonji C domain-containing protein JMJ30 regulates period length in the Arabidopsis circadian clock. Plant Physiol. 155, 906-915. doi: 10.1104/pp.110.167015

MacMillan, J. (2001). Occurrence of gibberellins in vascular plants, fungi, and bacteria. J. Plant Growth Regul. 20, 387-442. doi: 10.1007/s003440010038

Martens, S., and Forkmann, G. (1999). Cloning and expression of flavone synthase II from Gerbera hybrids. Plant J. 20, 611-618. doi: 10.1046/j.1365313X.1999.00636.x

Martens, S., Forkmann, G., Matern, U., and Lukacin, R. (2001). Cloning of parsley flavone synthase I. Phytochemistry 58, 43-46. doi: 10.1016/S0031-9422(01) 00191-1

Martens, S., Preuss, A., and Matern, U. (2010). Multifunctional flavonoid dioxygenases: flavonol and anthocyanin biosynthesis in Arabidopsis thaliana L. Phytochemistry 71, 1040-1049. doi: 10.1016/j.phytochem.2010.04.016

Matsuda, J., Okabe, S., Hashimoto, T., and Yamada, Y. (1991). Molecular cloning of hyoscyamine 6 beta-hydroxylase, a 2-oxoglutarate-dependent dioxygenase, from cultured roots of Hyoscyamus niger. J. Biol. Chem. 266, 9460-9464.

Matsumoto, S., Mizutani, M., Sakata, K., and Shimizu, B.-I. (2012). Molecular cloning and functional analysis of the ortho-hydroxylases of $p$-coumaroyl coenzyme A/feruloyl coenzyme A involved in formation of umbelliferone and scopoletin in sweet potato, Ipomoea batatas (L.) Lam. Phytochemistry 74, 49-57. doi: 10.1016/j.phytochem.2011.11.009

Meza, T. J., Moen, M. N., Vågbø, C. B., Krokan, H. E., Klungland, A., Grini, P. E., et al. (2012). The DNA dioxygenase ALKBH2 protects Arabidopsis thaliana against methylation damage. Nucleic Acids Res. 40, 6620-6631. doi: 10.1093/nar/gks327

Mielecki, D., Zugaj, D. L., Muszewska, A., Piwowarski, J., Chojnacka, A., Mielecki, M., et al. (2012). Novel AlkB dioxygenases-alternative models for in silico and in vivo studies. PLoS ONE 7:e30588. doi: 10.1371/journal.pone.0030588

Minami, H., Dubouzet, E., Iwasa, K., and Sato, F. (2007). Functional analysis of norcoclaurine synthase in Coptis japonica. J. Biol. Chem. 282, 6274-6282. doi: 10.1074/jbc.M608933200

Myllyharju, J. (2003). Prolyl 4-hydroxylases, the key enzymes of collagen biosynthesis. Matrix Biol. 22, 15-24. doi: 10.1016/S0945-053X(03)00006-4

Nakagawa, A., Minami, H., Kim, J.-S., Koyanagi, T., Katayama, T., Sato, F., et al. (2011). A bacterial platform for fermentative production of plant alkaloids. Nat. Commun. 2, 326. doi: 10.1038/ncomms1327

Nakajima, N., and Mori, H. (1990). Molecular cloning and sequence of a complementary DNA encoding 1-aminocyclopropane-l-carboxylate synthase induced by tissue wounding. Plant Cell 31, 1021-1029.

Nakanishi, H., Okumura, N., Umehara, Y., Nishizawa, N. K., Chino, M., and Mori, S. (1993). Expression of a gene specific for iron deficiency (Ids3) in the roots of Hordeum vulgare. Plant Cell Physiol. 34, 401-410.

Nakanishi, H., Yamaguchi, H., Sasakuma, T., Nishizawa, N. K., and Mori, S. (2000). Two dioxygenase genes, $I d s 3$ and $I d s 2$, from Hordeum vulgare are involved in the biosynthesis of mugineic acid family phytosiderophores. Plant Mol. Biol. 44, 199-207. doi: 10.1023/A:1006491521586

Okumura, N., Nishizawa, N., Umehara, Y., Ohata, T., Nakanishi, H., Yamaguchi, T., et al. (1994). A dioxygenase gene (Ids2) expressed under iron deficiency conditions in the roots of Hordeum vulgare. Plant Mol. Biol. 25, 705-719. doi: 10.1007/BF00029608

Pagnussat, G. C., Yu, H.-J., Ngo, Q. A., Rajani, S., Mayalagu, S., Johnson, C. S., et al. (2005). Genetic and molecular identification of genes required for female gametophyte development and function in Arabidopsis. Development 132, 603-614. doi: 10.1242/dev.01595

Pramod, K. K., Singh, S., and Jayabaskaran, C. (2010). Biochemical and structural characterization of recombinant hyoscyamine $6 \beta$-hydroxylase from Datura metel L. Plant Physiol. Biochem. 48, 966-970. doi: 10.1016/j.plaphy.2010. 09.003

Prescott, A. G., and John, P. (1996). Dioxygenases: molecular structure and role in plant metabolism. Annu. Rev. Plant Physiol. Plant Mol. Biol. 47, 245-271. doi: 10.1146/annurev.arplant.47.1.245

Runguphan, W., Glenn, W. S., and O'Connor, S. E. (2012). Redesign of a dioxygenase in morphine biosynthesis. Chem. Biol. 19, 674-678. doi: 10.1016/j. chembiol.2012.04.017
Saito, K., Kobayashi, M., Gong, Z., Tanaka, Y., and Yamazaki, M. (1999). Direct evidence for anthocyanidin synthase as a 2-oxoglutarate-dependent oxygenase: molecular cloning and functional expression of cDNA from a red forma of Perilla frutescens. Plant J. 17, 181-189. doi: 10.1046/j.1365-313X.1999.00365.x

Samanani, N., Liscombe, D. K., and Facchini, P. J. (2004). Molecular cloning and characterization of norcoclaurine synthase, an enzyme catalyzing the first committed step in benzylisoquinoline alkaloid biosynthesis. Plant J. 40, 302-313. doi: 10.1111/j.1365-313X.2004.02210.x

Schomburg, F. M., Bizzell, C. M., Lee, D. J., Zeevaart, J. A. D., and Amasino, R. M. (2003). Overexpression of a novel class of gibberellin 2-oxidases decreases gibberellin levels and creates dwarf plants. Plant Cell 15, 151-163. doi: 10.1105/tpc.005975

Shi, Y., Lan, F., Matson, C., Mulligan, P., Whetstine, J. R., Cole, P. A., et al. (2004) Histone demethylation mediated by the nuclear amine oxidase homolog LSD1. Cell 119, 941-953. doi: 10.1016/j.cell.2004.12.012

Shirley, B. (1996). Flavonoid biosynthesis: "new" functions for an "old" pathway. Trends Plant Sci. 1, 377-382. doi: 10.1016/S1360-1385(96)80312-8

Soares, V. L. F., Rodrigues, S. M., de Oliveira, T. M., de Queiroz, T. O., Lima, L. S., Hora-Júnior, B. T., et al. (2011). Unraveling new genes associated with seed development and metabolism in Bixa orellana L. by expressed sequence tag (EST) analysis. Mol. Biol. Rep. 38, 1329-1340. doi: 10.1007/s11033-010-0234-8

Spribille, R., and Forkmann, G. (1984). Conversion of dihydroflavonols to flavonols with enzyme extracts from flower buds of Matthiola incana. Z. Naturforsch. 39C, 714-719.

Sun, Q., and Zhou, D.-X. (2008). Rice jmjC domain-containing gene JMJ706 encodes H3K9 demethylase required for floral organ development. Proc. Natl. Acad. Sci. U.S.A. 105, 13679-13684. doi: 10.1073/pnas.0805901105

Takeuchi, T., Yamazaki, Y., Katoh-Fukui, Y., Tsuchiya, R., Kondo, S., Motoyama, J., et al. (1995). Gene trap capture of a novel mouse gene, jumonji required for neural tube formation. Genes Dev. 9, 1211-1222. doi: 10.1101/gad.9. 10.1211

Tarhonskaya, H., Szöllössi, A., Leung, I. K. H., Bush, J. T., Henry, L., Chowdhury, R., et al. (2014). Studies on deacetoxycephalosporin C synthase support a consensus mechanism for 2-oxoglutarate dependent oxygenases. Biochemistry 53, 2483-2493. doi: 10.1021/bi500086p

Thomas, S. G., Phillipsa, L., and Hedden, P. (1999). Molecular cloning and functional expression of gibberellin 2- oxidases, multifunctional enzymes involved in gibberellin deactivation. Proc. Natl. Acad. Sci. U.S.A. 96, 4698-4703. doi: 10.1073/pnas.96.8.4698

Tiainen, P., Myllyharju, J., and Koivunen, P. (2005). Characterization of a second Arabidopsis thaliana prolyl 4-hydroxylase with distinct substrate specificity. J. Biol. Chem. 280, 1142-1148. doi: 10.1074/jbc.M411109200

Tsukada, Y., Fang, J., Erdjument-Bromage, H., Warren, M. E., Borchers, C. H., Tempst, P., et al. (2006). Histone demethylation by a family of JmjC domaincontaining proteins. Nature 439, 811-816. doi: 10.1038/nature04433

Van der Straeten, D., Van Wiemeersch, L., Goodman, H. M., and Van Montagu, M. (1990). Cloning and sequence of two different cDNAs encoding 1aminocyclopropane-1-carboxylate synthase in tomato. Proc. Natl. Acad. Sci. U.S.A. 87, 4859-4863. doi: 10.1073/pnas.87.12.4859

Vazquez-Flota, F.,De Carolis, E., Alarco, A. M., and De Luca, V. (1997) Molecular cloning and characterization of desacetoxyvindoline-4-hydroxylase, a 2-oxoglutarate dependent-dioxygenase involved in the biosynthesis of vindoline in Catharanthus roseus (L.) G. Don. Plant Mol. Biol. 34, 935-948. doi: 10.1023/A:1005894001516

Vialart, G., Hehn, A., Olry, A., Ito, K., Krieger, C., Larbat, R., et al. (2012). A 2-oxoglutarate-dependent dioxygenase from Ruta graveolens L. exhibits pcoumaroyl CoA $2^{\prime}$-hydroxylase activity $\left(\mathrm{C}^{\prime} \mathrm{H}\right)$ : a missing step in the synthesis of umbelliferone in plants. Plant J. 70, 460-470. doi: 10.1111/j.1365313X.2011.04879.x

Vigani, G., Morandini, P., and Murgia, I. (2013). Searching iron sensors in plants by exploring the link among 2 -OG-dependent dioxygenases, the iron deficiency response and metabolic adjustments occurring under iron deficiency. Front. Plant Sci. 4:169. doi: 10.3389/fpls.2013.00169

Weiss, D., Baumert, A., Vogel, M., and Roos, W. (2006). Sanguinarine reductase, a key enzyme of benzophenanthridine detoxification. Plant. Cell Environ. 29, 291-302. doi: 10.1111/j.1365-3040.2005.01421.x

Williams, C. A., Harborne, J. B., Geiger, H., and Hoult, J. R. S. (1999). The flavonoids of Tanacetum parthenium and T. vulgare and their anti-inflammatory properties. Phytochemistry 51, 417-423. doi: 10.1016/S0031-9422(99)00021-7 
Wilmouth, R. C., Turnbull, J. J., Welford, R. W. D., Clifton, I. J., Prescott, A. G., and Schofield, C. J. (2002). Structure and mechanism of anthocyanidin synthase from Arabidopsis thaliana. Structure 10, 93-103. doi: 10.1016/S09692126(01)00695-5

Woodward, A. W., and Bartel, B. (2005). Auxin: regulation, action, and interaction. Ann. Bot. 95, 707-735. doi: 10.1093/aob/mci083

Xu, Y. L., Li, L., Wu, K., Peeters, A. J. M., Gage, D. A., and Zeevaart, J. A. B. (1995). The GA5 locus of Arabidopsis thaliana encodes multifunctional gibberellin 20-oxidase: molecular cloning and functional expression. Proc. Nat. Acad. Sci. U.S.A. 92, 6640-6644. doi: 10.1073/pnas.92. 14.6640

Yamaguchi, S. (2008). Gibberellin metabolism and its regulation. Annu. Rev. Plant Biol. 59, 225-251. doi: 10.1146/annurev.arplant.59.032607.092804

Yang, W., Jiang, D., Jiang, J., and He, Y. (2010). A plant-specific histone H3 lysine 4 demethylase represses the floral transition in Arabidopsis. Plant J. 62, 663-673. doi: 10.1111/j.1365-313X.2010.04182.x

Yu, X., Li, L., Li, L., Guo, M., Chory, J., and Yin, Y. (2008). Modulation of brassinosteroid-regulated gene expression by Jumonji domain-containing proteins ELF6 and REF6 in Arabidopsis. Proc. Natl. Acad. Sci. U.S.A. 105, 7618-7623. doi: 10.1073/pnas.0802254105

Zhang, K., Halitschke, R., Yin, C., Liu, C.-J., and Gan, S.-S. (2013). Salicylic acid 3-hydroxylase regulates Arabidopsis leaf longevity by mediating salicylic acid catabolism. Proc. Natl. Acad. Sci. U.S.A. 110, 14807-14812. doi: 10.1073/pnas. 1302702110

Zhang, Z., Ren, J.-S., Clifton, I. J., and Schofield, C. J. (2004). Crystal structure and mechanistic implications of 1-aminocyclopropane-1-carboxylic acid oxidase - the ethylene-forming enzyme. Chem. Biol. 11, 1383-1394. doi: 10.1016/j.chembiol.2004.08.012

Zhao, Z., Zhang, Y., Liu, X., Zhang, X., Liu, S., Yu, X., et al. (2013). A role for a dioxygenase in auxin metabolism and reproductive development in rice. Dev. Cell 27, 113-122. doi: 10.1016/j.devcel.2013.09.005

Ziegler, J., and Facchini, P. J. (2008). Alkaloid biosynthesis: metabolism and trafficking. Annu. Rev. Plant Biol. 59, 735-769. doi: 10.1146/annurev.arplant. 59.032607.092730

Conflict of Interest Statement: The authors declare that the research was conducted in the absence of any commercial or financial relationships that could be construed as a potential conflict of interest.

Received: 18 August 2014; accepted: 16 September 2014; published online: 09 October 2014.

Citation: Farrow SC and Facchini PJ (2014) Functional diversity of 2oxoglutarate/Fe(II)-dependent dioxygenases in plant metabolism. Front. Plant Sci. 5:524. doi: 10.3389/fpls.2014.00524

This article was submitted to Plant Metabolism and Chemodiversity, a section of the journal Frontiers in Plant Science.

Copyright (c) 2014 Farrow and Facchini. This is an open-access article distributed under the terms of the Creative Commons Attribution License (CC BY). The use, distribution or reproduction in other forums is permitted, provided the original author(s) or licensor are credited and that the original publication in this journal is cited, in accordance with accepted academic practice. No use, distribution or reproduction is permitted which does not comply with these terms. 